Article

\title{
Complementary Optimization of Hydropower with Pumped Hydro Storage-Photovoltaic Plant for All-Day Peak Electricity Demand in Malawi
}

\author{
Evance Chaima ${ }^{1,2, * \mathbb{D}}$, Jijian Lian ${ }^{1,2, *}$, Chao Ma ${ }^{1,2}$, Yusheng Zhang ${ }^{1,2}$ and Sheila Kavwenje ${ }^{3}$ \\ 1 State Key Laboratory of Hydraulic Engineering Simulation and Safety, Tianjin University, Tianjin 300350, \\ China; mac_tiu@126.com (C.M.); zhangyusheng01@tyut.edu.cn (Y.Z.) \\ 2 School of Civil Engineering, Tianjin University, Tianjin 300350, China \\ 3 School of Environmental Engineering, Tianjin University, Tianjin 300350, China; skavwenje@luanar.ac.mw \\ * Correspondence: eva_chaima@yahoo.com (E.C.); jjlian@tju.edu.cn (J.L.)
}

Citation: Chaima, E.; Lian, J.; Ma, C.; Zhang, Y.; Kavwenje, S. Complementary Optimization of Hydropower with Pumped Hydro Storage-Photovoltaic Plant for All-Day Peak Electricity Demand in Malawi. Energies 2021, 14, 4948. https://doi.org/10.3390/en14164948

Academic Editors: Victor Becerra and Helena M. Ramos

Received: 2 July 2021

Accepted: 9 August 2021

Published: 12 August 2021

Publisher's Note: MDPI stays neutral with regard to jurisdictional claims in published maps and institutional affiliations.

Copyright: (c) 2021 by the authors. Licensee MDPI, Basel, Switzerland. This article is an open access article distributed under the terms and conditions of the Creative Commons Attribution (CC BY) license (https:/ / creativecommons.org/licenses/by/ $4.0 /)$.

\begin{abstract}
Solar energy is currently dispatched ahead of other renewable energy sources. For the first time, this study presents a concept of exploiting temporary-periodical runoff discharge in the Shire River. Pumped hydro storage-photovoltaic plant (PHS-PV) was optimized to satisfy the all-day peak electricity demand in Malawi. The effect of varying the net head on the PHS system in both the generation and pumping operation modes was investigated. The bi-objective optimization evaluated the system reliability for day-time and night-time operation together with implied costs of investment for the whole system. The optimized system generated above $53 \%$ of added power as contrasted to single-source power generation from the existing hydropower plants. The estimated optimal capacities were $182 \mathrm{MWp}$ (solar PV) and $86 \mathrm{MW}$ (PHS plant). These additional optimal capacities achieved a 99.8\% maximum system reliability (Loss of Power Supply Probability—LPSP—of $0.2 \%$ ) and Levelized Cost of Energy_LCOE—of 0.13 USD/kWh. The overall investment cost of the PHSPV system was estimated at 671.23 USD for an LPSP of $0.20 \%$. The net head varies from 15.5 to $17.8 \mathrm{~m}$ with an impact on electricity generation of the PHS-PV system. More notably, the PHS-PV production matches with daily day-time and night-time peak loads and functions as a peaking plant.
\end{abstract}

Keywords: optimization; renewable energy generation; photovoltaic; pumped hydro storage; peak electricity demand; load satisfaction

\section{Introduction}

Most developing countries, including Malawi, lag in implementing and developing large-scale renewable energy technologies. These renewable energy technologies are currently critical to achieving the 2030 agenda and sustainable development goals. One of the goals that is featured in this agenda seeks to provide universal access to affordable, reliable, and modern energy services as well as to increase the share of renewable energy in the global energy mix by the year 2030 [1]. Energy generation for the power system in Malawi strongly depends on the runoff discharge in the Shire River and water levels in Lake Malawi. However, there is a large peak discharge during the rainy season and a substantially low runoff discharge during the dry season in the Shire River. The power system in Malawi for the existing run-of-river plants has less installed capacities to utilize large peak runoff discharge available during the rainy season. For this reason, the country's electricity generation does not meet load demand for all year round, even more so especially during the dry season when the runoff discharge does not meet the base load. Furthermore, Malawi's terrain conditions limit the development of a reservoir with a large regulation capacity through which operators can redistribute runoff between the rainy season and the dry season for a better energy supply. Thus, innovative ways are required to sustain and stabilize the power supply and bolster the country's economic growth. Considering 
the rich solar resource in Malawi, the use of the PHS-PV system allows the exploitation of flows that are periodical for energy production. For example, during typical dry years or day-time peak loads, the PV can complement PHS for electricity generation and allow more water to be used for other purposes or be saved. While during wet years or during night-time peak loads more water can be utilized with the availability of the PHS system after day-time pumping or day-time water saving by the use of excess power from the PV plant instead of the hydroelectric plant.

Some studies reported that energy generation characteristics of hydropower and solar $\mathrm{PV} /$ wind are widely characterized by randomness and intermittency and are affected by the availability of runoff, wind speed, solar radiation, ambient temperature, and other factors [2,3]. Thus, it is vital to integrate hybrid renewable energy technologies such as the PHS-PV systems. These hybrid systems can effectively overcome drawbacks such as instability, unreliability, unpredictability, randomness, and variability common in single-source renewable energy technologies [4-6]. For instance, pumped storage is a highly mature centralized storage technology with a high power and energy capacity capable of accelerating the integration of large-scale renewable energy sources (RES) [7]. Other studies described PHS-PV systems as having a sizeable volume, lengthy storage period, high efficiency and reliability, and are the most cost-effective large-scale storage technology currently available [8]. In their review, Deane et al. [9] showcased that PHS-PV systems have a flexible generation that can deliver both up and down-regulation in the power system. They also reported that these PHS-PV systems' speedy start abilities render them appropriate for black starts and running of spinning, including standing reserves. Ardizzon et al. [10] stated that there is renewed interest in pumped hydro energy storage plants because of the required integration of a significant share of intermittent renewable energy sources in the grid. These hybrid systems are likely adaptable to provide frequency regulation. Still, others carried out innovative design solutions and optimal operating strategies for hybrid renewable energy systems based on simple algorithms and more complex optimization theories. For instance, Margeta and Glasnovic [11] analyzed a hybrid solar and hydroelectric (SHE) system as a distinctive technological concept of the sustainable energy system that could offer an uninterrupted electric power and energy supply to its consumers. Glasnovic et al. [12] presented an artificial water inflow created by a photovoltaic (PV) or solar thermal (ST) generator that pumped water into the upper water/energy storage of a pump storage hydroelectric (PSH) system for uninterrupted green energy production. Hydropower's flexibility and storage capacity allows it to improve grid stability and supports the deployment of other intermittent renewable energy sources such as wind and solar [13]. A hydropower-solar PV system controls the hydropower output in real-time by complementing the load and PV output characteristics to meet the load demand and reduce PV curtailments [14]. In their study, Kougias et al. [15] developed a method that examined the degree of time complementarity between small hydropower stations (SPHS) and adjacent solar PV systems (SPVS) as an approach to explore where different RES operated in synergy. François et al. [16] examined the skill of various hydrological prediction methods. They predicted complementarity between run-of-the-river hydropower and solar power in data-sparse mountain basins in the Eastern Italian Alps. They found the hydrological model performing better in rain-fed catchments. Jurasz and Ciapała [17] presented a novel approach to overcoming the inherent variability of photovoltaics (PV) by combining them with a run-off-river (ROR) power plant to smooth the energy exchange with the grid.

Other studies widely investigated optimal designs in hybrid hydro storage-solar PV systems for stand-alone/off-grid systems and proposed to be cost-effective. In their analysis, Papaefthymiou et al. [18] sized the main hybrid power stations (PHS) components (hydro turbines, pumps, wind farms, and reservoirs) to maximize the return on the PHS investment and RES penetration. Ma et al. [19] described the system reliability and economic criteria as a benchmark for optimization by applying mathematical models for the main components of PHS-PV using the genetic algorithm (GA) and Pareto optimality theory. On the same note, Mousavi et al. [20] developed an improved mathematical model 
for a PHS-PV system considering electrical, mechanical, and hydraulic losses. Others analyzed that the PHS-PV potential increased the penetration level of renewable energy in isolated power systems in Gran Canaria (Canary Islands) [21]. Juan et al. [22] assessed the contribution of a PHS-PV system to cut the system scheduling costs by employing the hydrothermal weekly unit commitment model. Moreover, other researchers examined the function of a local pumped hydro energy storage in interconnected (IC) island grids with high wind power production. The system was found to be a cost-effective and desirable solution when mixed with local large-scale wind energy (WE) and pumped hydro storage (PHS) units [23]. Additionally, Chen et al. [24] utilized PHS in a hybrid power system (PHS) to cushion the effect of the sporadic behavior of wind energy. As observed, an extensive optimal sizing of complementary renewable energy systems is paramount. Various investigations suggested either the use of single or multi-objective mathematical models to optimize hybrid renewable energy systems by the use of indicators such as the loss of power supply probability (LPSP) [25]. Scholars such as Abdul Aziz et al. [26] derived the optimized capacity of a stand-alone PV technology by minimizing the LPSP. Ould Bilal et al. [27] optimized the design of a hybrid solar-wind-battery system by minimizing the annualized cost system and the LPSP. Additionally, Maleki and Pourfayaz et al. [28] established an optimized size of an autonomous hybrid photovoltaic/wind/battery power system with the LPSP technology using evolutionary algorithms. Others used the LPSP to support decisions on installation and optimal sizing of PV panels for remote areas [29]. A review by Lian et al. [30] also presented a comprehensive evaluation of the application of the LPSP regarding recent sizing methodologies of hybrid renewable energy technologies. Other researchers applied the Levelized cost of energy [31], net present value and life cycle cost [32], and total annualized costs (TAC) [33] to optimize the capacity of hybrid renewable energy technologies. Moreover, recently a good number of software analyzing tools, including genetic algorithms (GA), have been applied to cost-effectively obtain optimal results. Ma et al. [34] employed GAs in MATLAB to optimize the capacity and system total cost of the PV generator and pumped storage system for power supply in remote areas. Luo et al. [35] applied GAs in MATLAB to optimally size isolated grids with a wind power and energy storage system.

Currently, a gap in knowledge exists in finding feasible solutions that could improve the utilization of streamflow with periodical and temporary run-off characteristics in runoff river plants. Specifically, the current study focused on runoff river plants with limited terrain conditions to allow the development of a reservoir with a large regulation capacity and hydropower station with a large installed capacity. Based on the review on some published articles related to PHS-PV systems, the researchers found that investigations related to PHS-PV systems paid more attention to the optimal design of PHS-PV to just regulate the output fluctuation of solar energy, peak shaving, smoothing the energy demand curve, or stabilizing the energy flow using a pump station [17]. Some studies proposed PHS-PV-wind systems as a way to increase solar energy penetration $[19,21]$ particularly for small and isolated power systems in remote areas leading to an increase in capacity of $40 \%$ of the maximum wind penetration level during peak hours [21]. Simão and Ramos [36] investigated the combined generation of hydro, solar, and wind for the best challenge of energy storage flexibility, reliability, and sustainability. They found that the combined production showcased that technically the pumped hydro storage with wind and PV was the best solution to realize energy autonomy and improve its flexibility and dependability. Pérez-Díaz and Jiménez [22] assessed the contribution of a pumped-storage hydropower plant in reducing the system scheduling costs by using a hydrothermal weekly unit commitment model. Chen et al. [24] presented a mathematical model for the design of a hybrid power system (HPS) in which pumped hydro storage was just used to store provisional excess electric power. Zhang et al. [25] established a bi-objective mathematical model that only minimized the change between the daily output processes of the hydro/PV combined system and the setting-up of a characteristic load process whilst increasing the daily power generation of the hydro/PV combined system. The research hypothesis in this 
study is that a mixture of hydroelectric and PHS-PV offers an invaluable add-on to power production in Malawi. This study is the first attempt to introduce an optimization method of exploiting temporary-periodic runoff discharge for the Shire River scenario. This was achieved by combining hydro and PHS-PV to provide considerable benefits for electric power generation and satisfy the day and night-time demand of the grid in Malawi. The cascade hydropower production and the PHS-PV will have the same transmission set-up, thereby reducing installation and transmission expenses. In the paper, the effect of the net head variation on system operation and electricity production was considered. The net head effect on power generation was investigated since several researchers have used constant head by assuming that the sum of the stored energy in both the upper and the lower reservoirs is constant. However, due to a large variation in the net head of a PHS throughout the entire scheduling horizon, such assumptions could lead to inaccurate and inappropriate results.

The goal for this study was to analyze and determine a large-scale combination, operation, and optimization framework for dispatching the PHS-PV system in the cascaded hydropower plants to meet the all-day peak electricity demand in Malawi. The current study's main contributions are:

- Exploring the PHS-PV system and showcasing the concept of exploiting the temporaryperiodic flow in run-of-river plants with a small reservoir regulation capacity for meeting the all-day peak electricity demand in Malawi.

- Developing the quasi-steady operational framework for the exploitation of a temporaryperiodic flow and PHS-PV power generation.

- Incorporating the net head effects for the PHS-PV in both generating and pumping modes in the model.

The above three points need to be evaluated and incorporated into the model for the successful execution of the optimization process and proper analysis. The results from this model can be applied to regions with similar special run-off characteristics, the limited geological landscape for large-scale reservoir construction, and climate such as the Mediterranean regions. The rest of the paper is arranged as follows: Section 2 introduces the materials and methods used in the analysis; Section 3 showcases the analyzed results; Section 4 presents the discussion and conclusions are presented in Section 5.

\section{Materials and Methods}

\subsection{Linear Optimisation Model for the Cascade Hydro/PHS-PV Combined Electric Power System}

Malawi's power system experiences two peak load demands; one during the day and another during the night. The PHS-PV, such as other hybrid electric plants, has the capacity of producing electricity only in day-time once the solar irradiance is in abundance. During the day-time peak load demand, the PHS-PV can deliver sufficient electricity to match existing load demand in the main grid. The PHS-PV plant can generate the required amount of electricity as an alternative to using water runoff from the run-off-river cascade hydropower plants to produce extra electricity to meet the peak demand. In this study, the assumption was that the cascade hydroelectric plant usually generates the required base electricity dispatch from the grid operator. The hydro pumped storage and Solar PV plants merely play an important function of satisfying the peak load demand encountered in day-time and night-time. Full exploitation of solar energy is then crucial to optimize the operation of the cascade hydropower and PHS-PV plants. Mathematical models and methods were performed to obtain the optimum results for the combination of cascade hydropower and PHS-PV plants by employing the following schematic diagram in Figure 1. 
$C(t)$

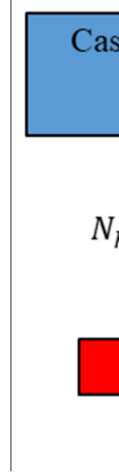

$H(t)$

Cascade hydropower plants

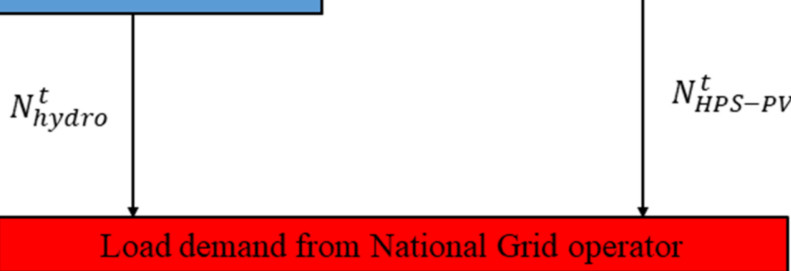

$L(t)$

Figure 1. The schematic diagram for the optimization problem.

\subsubsection{Objective Function}

In this study, the rationale to combine cascade hydro and PHS-PV power was to save water in the upper reservoir through pumping from the lower reservoir whenever solar power out was in excess during daytime. This conserved water could be utilized for power generation through turbines during night-time peak hours to satisfy load demand. The arrangement could minimize stress on the electricity production machines at the cascade hydropower plants specifically in the peak demand intervals of the day. Likewise, the incorporation is critical in the PHS-PV system due to the fact that the cascade hydropower plants might as well complement whenever there is intermittent and discontinued solar irradiance. The sum of electricity output from both the cascade hydropower and PHS-PV combined system will be sufficient besides minimal differences and will fully operate at optimum level. The goal of this study's optimization problem was maximization of total energy produced from the cascade hydropower/PHS-PV hybrid system whilst satisfying all the applicable constraints. Maximization of generated power for the entire system in the whole scheduling horizon (time period) is a crucial objective in order to operate any electricity production scheme. The objective function for linear optimization in this study is expressed in Equation (1) and can be written as:

$$
Z=\operatorname{Max} \sum_{t=1}^{T}\left(N_{\text {hydro }}^{t}+N_{P H S-P V}^{t}\right) \times \Delta t
$$

The total power output produced by the solar PHS and PV output is expressed in Equation (2).

$$
N_{P H S-P V}^{t}=N_{P H S}^{t}+N_{P V}^{t}
$$

The power output produced by the PHS plant is expressed in Equation (3).

$$
N_{P H S}^{t}=\left(A \times Q_{P H S}^{t} \times H_{T-P H S}^{t}\right) / 1000
$$

The solar PV electricity output's estimation was based on a model established by the National Renewable Energy Laboratory (NREL) [36] using the formula in Equation (4).

$$
N_{P V}^{t}=X_{p}\left(\frac{R_{t}}{R_{b}}\right)\left[1+\alpha_{p}\left(T_{c}-T_{b}\right)\right]
$$

The power output produced by cascade hydropower stations is expressed in Equation (5).

$$
N_{\text {hydro }}^{t}=\left(A \times Q_{\text {hydro }}^{t} \times H_{T-h y d r o}^{t}\right) / 1000
$$

where $N_{h y d r o}^{t}$ denotes the power output from cascade hydropower plants in $t$ th time interval $(\mathrm{kW}) ; N_{P H S-P V}^{t}$ denotes the total power output produced by the PHS-PV hybrid system 
in $t$ th time interval (kW); $\Delta t$ denotes the change in time interval (hrs.); $N_{P H S}^{t}$ denotes the power output at the hydro pumped storage plant in $t$ th time interval (kW); $N_{P H S}^{t}$ denotes power output of the PHS plant in $t$ th time interval $(\mathrm{kW}) ; Q_{H P S}^{t}$ denotes the average generation flow for the PHS system in $t$ th time interval $\left(\mathrm{m}^{3} / \mathrm{s}\right) ; H_{T-P H S}^{t}$ denotes the net head variation for the PHS system in th time interval $(\mathrm{m}) ; Q_{h y d r o}^{t}$ denotes the average generation flow for the cascade hydropower plants in $t$ th time interval $\left(\mathrm{m}^{3} / \mathrm{s}\right) ; H_{T-h y d r o}^{t}$ denotes the net head variation for the cascade hydropower plants in th time interval $(\mathrm{m})$; $\mathrm{A}=\left(\frac{\rho \times g}{\eta_{p}}\right)$ denotes a dimensionless constant; $\rho$ denotes the density of water $\left(1000 \mathrm{~kg} / \mathrm{m}^{3}\right)$; $g$ denotes the acceleration due to gravity $\left(9.8 \mathrm{~m} / \mathrm{s}^{2}\right) ; \eta_{p}$ denotes the overall pumping efficiency. $N_{P V}^{t}$ denotes the power output of the solar PV plant in $t$ th time interval $(\mathrm{kW})$; $X p$ denotes the rated power output of the PV plant $(\mathrm{kW}) ; R_{t}$ denotes the actual intensity of solar radiation $\left(\mathrm{kW} / \mathrm{m}^{2}\right) ; R_{b}$ denotes the intensity of solar radiation under standard test conditions $\left(1 \mathrm{~kW} / \mathrm{m}^{2}\right) ; \alpha_{p}$ denotes the power output temperature coefficient of the solar cell modules $\left({ }^{\circ} \mathrm{C}\right) ; T_{c}$ denotes the actual temperature of the solar cell modules $\left({ }^{\circ} \mathrm{C}\right)$, and $T_{b}$ denotes the temperature of the solar cell modules under standard test conditions $\left(25^{\circ} \mathrm{C}\right.$.

\subsubsection{Constraints}

The key constraints for the hybrid system comprise those related to power output dispatched by cascade hydro and PHS-PV plant to the operator of the power grid and the power grid capacity expressed in Equations below:

1. The decision variables should be positive values; the total electricity output dispatched to meet load demand from both cascade hydropower and PHS-PV plants should constantly be positively expressed in Equations (6) and (7) below:

$$
\begin{gathered}
N_{\text {hydro }}^{t} \geq 0 \\
N_{P H S-P V}^{t} \geq 0
\end{gathered}
$$

2. The amount of power dispatched by the PHS-PV plant and cascade hydropower plants in the th time interval $(t)$ should constantly be no more than or equal to the maximum electricity the corresponding system can produce and is expressed in Equations (8) and (9) below:

$$
\begin{gathered}
N_{\text {hydro }}^{t} \leq C_{\max } \\
N_{P H S-P V}^{t} \leq H_{\max }
\end{gathered}
$$

where $C_{\max }$ and $H_{\max }$ are the upper limits of power that the cascade hydropower and PHS-PV power plants can produce

3. The total electricity generated from both cascade hydropower and PHS-PV plants in the $t$ th time interval $(t)$ should constantly be no more than or equal to the load demand $L(t)$ as expressed in Equation (10) below:

$$
N_{\text {hydro }}^{t}+N_{P H S-P V}^{t} \leq L(t)
$$

4. Constraints such as upper and lower reservoir storage, upper and lower reservoir water level, release flow, and non-negative constraints are expressed in Equations (11)-(16) below:

- Upper reservoir water storage and water level constraints:

$$
\begin{gathered}
V_{\min }^{U, t} \leq V_{U, t} \leq V_{\max }^{U, t} \\
z_{1, t}^{\min } \leq z_{1, t} \leq z_{1, t}^{\max }
\end{gathered}
$$


- Lower reservoir storage and water level constraints:

$$
\begin{aligned}
& V_{\text {min }}^{L, t} \leq V_{L, t} \leq V_{\text {max }}^{L, t} \\
& z_{2, t}^{\min } \leq z_{2, t} \leq z_{2, t}^{\max }
\end{aligned}
$$

- Reservoir flow release constraints:

$$
Q_{\text {min }}^{t} \leq Q_{P H S}^{t}+Q_{s}^{t} \leq Q_{\text {max }}^{t}
$$

- Non-negative constraints:

The above variables are non-negative values.

where $V_{\text {min }}^{U, t}$ and $V_{\text {max }}^{U, t}$ denote minima and maxima boundaries for upper reservoir volume storage in the $t$ th time interval, respectively $\left(\mathrm{m}^{3}\right) ; V_{\text {min }}^{L, t}$ and $V_{\text {max }}^{L, t}$ denote minima and maxima boundaries for lower reservoir volume storage in the $t$ th time interval, respectively $\left(\mathrm{m}^{3}\right) ; V_{U, t}$ and $V_{L, t}$ denote the volume in upper and lower reservoir in the $t$ th time interval $\left(\mathrm{m}^{3}\right)$, respectively; $z_{1, t}^{\min }$ and $z_{1, t}^{\max }$ denote minima and maxima boundaries for upper reservoir water levels in the th time interval, respectively $(\mathrm{m}) ; z_{2, t}^{\min }$ and $z_{2, t}^{\max }$ denote minima and maxima boundaries for lower reservoir water levels in the th time interval, respectively $(\mathrm{m}) ; z_{1, t}$ and $z_{2, t}$ denote the water level in upper and lower reservoir in the $t$ th time interval (m), respectively; $Q_{\text {min }}^{t}$ and $Q_{\text {max }}^{t}$ denote minima and maxima boundaries for upper reservoir discharge in the $t$ th time interval, respectively $\left(\mathrm{m}^{3} / \mathrm{s}\right) ; Q_{P H S}^{t}$ denote upper reservoir discharge into the turbine for hydropower generation in the $t$ th time interval, respectively $\left(\mathrm{m}^{3} / \mathrm{s}\right) ; Q_{s}^{t}$ denote upper reservoir spillage in the $t$ th time interval, respectively $\left(\mathrm{m}^{3} / \mathrm{s}\right)$.

\subsubsection{The Proposed Energy Supply Mode}

The PHS-PV hybrid system comprises of a large-scale utility solar PV plant having PV modules, inverters, and control center and the hydro-pumped storage component having a motor-pump unit, charge, and discharge pipes, upper reservoir (UR), lower reservoir (LR), and turbine-generator unit as shown in Figure 2. The PHS-PV system is connected to the main grid together with the cascade hydropower plants. Throughout the whole process, the cascade hydropower plants generate the least amount of power to satisfy the dispatch electricity fixed by the operator of the grid, i.e., base power generation for the whole day. Additionally, the PHS-PV system only satisfies the peak electricity with PV power output satisfying a fraction of the day-time peak load and PHS system only meeting the peak load experienced during night time when there is no solar power as a complementary power source to the cascaded hydropower generation. The system set-up involves the storage of surplus energy dispatched from PV as hydraulic energy during day time by dispatching the excess energy to PHS system to pump water from the lower reservoir to the upper reservoir. The stored hydraulic energy is discharged via the turbine-generator unit to produce hydroelectricity at times when there is a need.

\subsubsection{The Quasi-Steady Operating Strategy for the PHS-PV Mode}

The operating plan for the PHS-PV mode, whose results are presented in Figure 3, was designed to obtain optimal results. The steps below describe the specific details:

1. At any time interval, power output was calculated as expressed in Equation (17) below:

$$
N_{1}=\left(N_{h y d r o}^{t}+N_{P H S-P V}^{t}\right)-L(t)
$$


2. At any time interval, if power output was more than load demand, any excess power was dispatched to the pump for reservoir charging as expressed in Equation (18) below:

$$
N_{P H S}^{t}=N_{1} \text { if } N_{1}>0
$$

3. During this period, pumping of water from lower reservoir to upper reservoir for night storage was in operation in the PHS-PV system. Additionally, the corresponding pump discharge, head water level, volume in lower reservoir, and updated head water level were calculated in the $t$ th period, respectively, as expressed in Equations (19)-(22) below:

$$
\begin{gathered}
Q_{P}^{t}=\left(N_{P H S}^{t} \times 0.85\right) / H_{T-P H S}^{t} \\
h_{2, t+1}=\frac{\left(Q_{i n}^{t}-Q_{P}^{t}+Q_{d}^{t}-Q_{S}^{t}\right)}{A} \times 3600 \\
V_{L w}=A_{L w} \times h_{2, t+1} \\
H_{T-P H S}^{t}=Z_{t}+h_{1, t+1}+h_{2, t+1}
\end{gathered}
$$

4. At any time interval, if power output was less than load demand, then load demand was not fully met with the system experiencing a shortage of power supply as expressed in Equation (23) below:

$$
N_{S}^{t}=\operatorname{Abs}\left(N_{1}\right) \text { if } N_{1} \leq 0
$$

5. During this period, the turbine operation of the PHS-PV system was dispatched as a complementary source of power supply to the system for load satisfaction. The corresponding turbine release resulting from energy shortage, head water level, volume in lower reservoir, and updated head water level were calculated in the $t$ th period, respectively, and expressed in Equations (24)-(28) below:

$$
\begin{gathered}
Q_{P H S}^{t}=\left(N_{S}^{t}\right) / A \times H_{T-P H S}^{t} \\
h_{1, t+1}=\frac{\left(Q_{i n}^{t}+Q_{P}^{t}+Q_{P H S}^{t}-Q_{S}^{t}\right)}{A} \times 3600 \\
V_{U p}=A_{U p} \times h_{1, t+1} \\
H_{T-P H S}^{t}=Z_{t}+h_{1, t+1} \\
N_{P H S}^{t}=Q_{P H S}^{t} \times A \times H_{T-P H S}^{t}
\end{gathered}
$$

6. At any time interval, if a shortage in power output was not fully satisfied by the system power output (defined as the sum of cascade hydropower output, PV power output, and turbine operation for PHS-PV). Then, the loss of power supply probability (LPSP) and LCOE was estimated expressed in Equations (29)-(31) below:

$$
\begin{gathered}
N_{\text {Supply }}^{t}=N_{P V}^{t}+N_{P H S}^{t} \\
L P S P=0 \text { if } N_{\text {Supply }}^{t} \geq L(t) \\
L P S P=0 \text { if } N_{\text {Supply }}^{t} \geq L(t)
\end{gathered}
$$

7. A bi-objective problem was established and applied in Genetic Algorithm (GA) for optimization in MATLAB.

8. The volume and water levels inside the upper and lower reservoirs were constantly restored based on calculated pumping storage. The constraints and terms used in Section 2.1.2 were also applied.

where $N_{1}$ denote total power output produced by the whole system in $t$ th time interval $(\mathrm{kW}) ; N_{S}^{t}$ denote shortage in power output produced by the whole system $t$ th time interval 
$(\mathrm{kW}) ; Q_{P}^{t}$ denote pumping rate from lower reservoir into the upper reservoir for water storage in the th time interval $\left(\mathrm{m}^{3} / \mathrm{s}\right) ; A_{U p}$ denotes total area for the upper reservoir $\left(\mathrm{m}^{2}\right)$; $A_{L w}$ denotes total area for the lower reservoir $\left(\mathrm{m}^{2}\right)$.

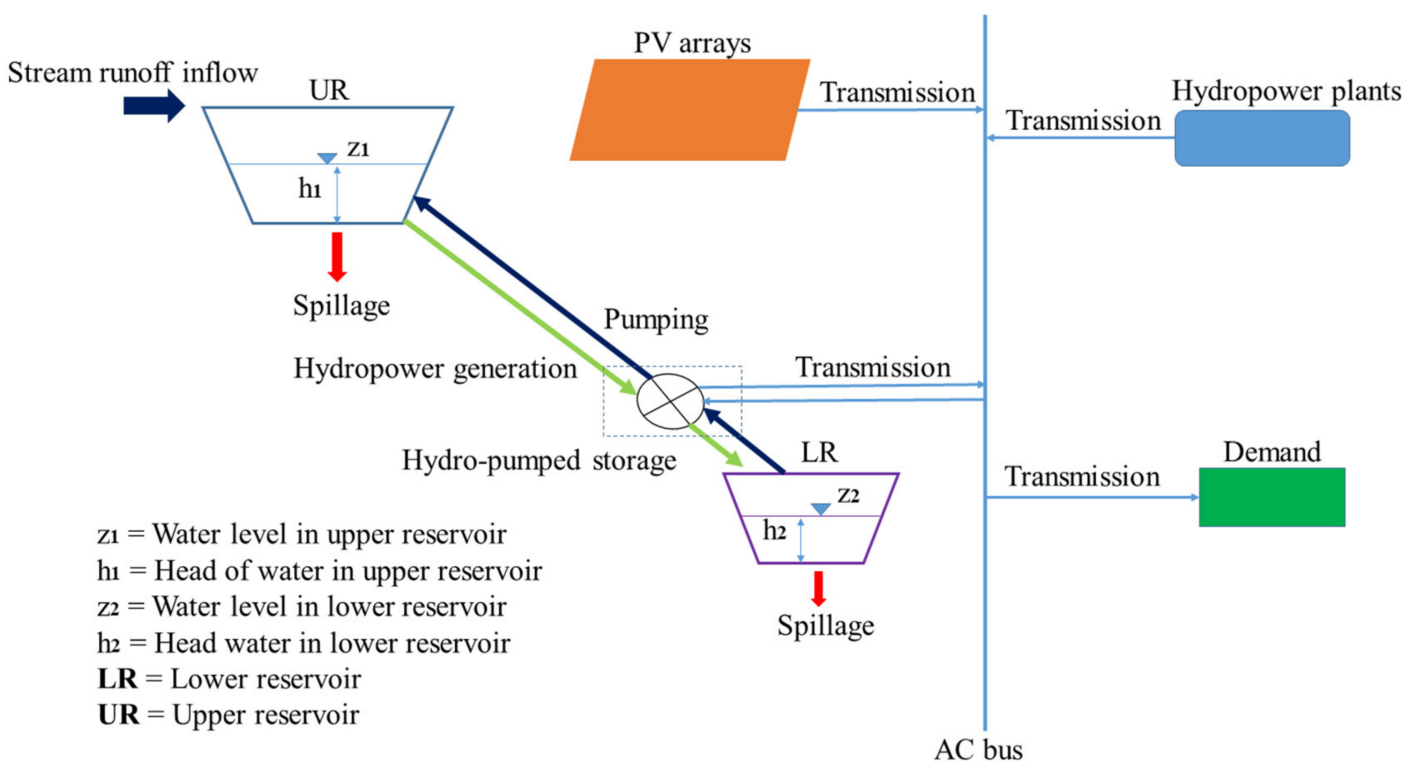

Figure 2. Illustration for system power supply mode.

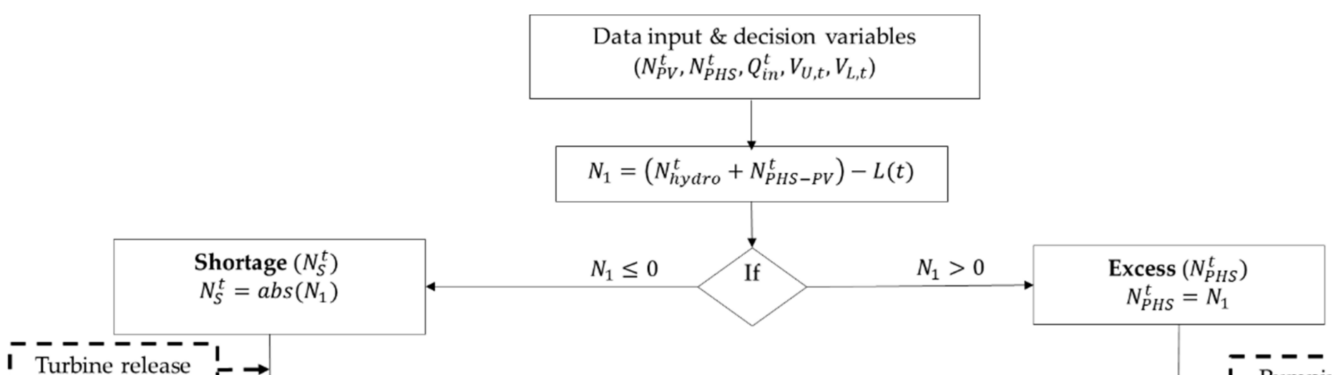

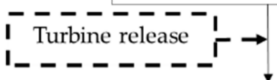

- Calculate corresponding turbine release resulting from shortage of energy, $Q_{P H S}^{t}=\left(N_{S}^{t}\right) /\left(A * H_{T-P H S}^{t}\right)$

- Input new head water level of upper reservoir in the th period,

$$
h_{1, t+1}=h_{1}+\frac{\left[Q_{i n}^{t}+Q_{P}^{t}-Q_{P H S}^{t}-Q_{s}^{t}\right]}{A} * 3600
$$

- Estimate upper reservoir volume, $V_{U, t}=A_{U p}{ }^{*} h_{1, t+1}$ in the $t$ th period

- Obtain updated total head for turbine generation in the th period,

$$
H_{T-P H S}^{t}=Z_{t}+h_{1, t+1}
$$

- Estimate hydropower generated by turbine based on $Q_{d}^{t}$ and $H_{T-P H S}^{t}$ in the th period $N_{P H S}^{t}=Q_{P H S}^{t} * A * H_{T-P H S}^{t}$
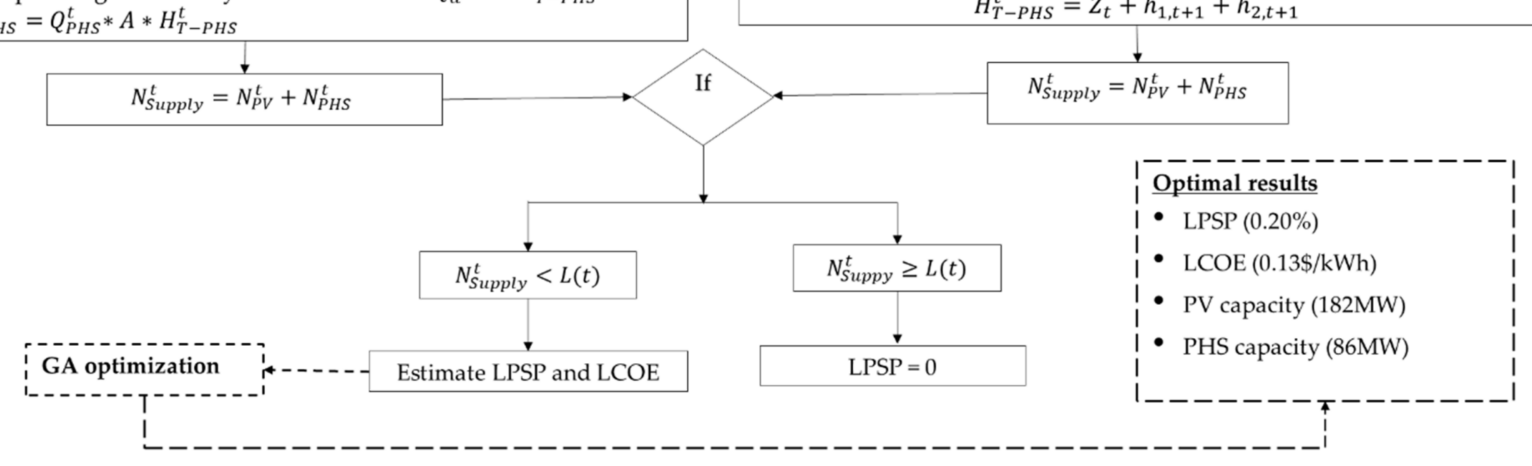

Figure 3. Detailed flow chart of the quasi-steady operation model.
- Calculate corresponding pumping discharge resulting from excess energy in the $t$ th period,

$$
Q_{P}^{t}=\left(N_{P H S}^{t} * 0.85\right) / H_{T-P H S}^{t}
$$

- Input new head water level of lower reservoir in the $t$ th period,

$$
h_{2, t+1}=h_{2}+\frac{\left[Q_{i n}^{t}-Q_{P}^{t}+Q_{P H S}^{t}-Q_{S}^{t}\right]}{(A)} * 3600
$$

- Estimate lower reservoir volume, $V_{L, t}=A_{L w}{ }^{*} h_{2, t+1}$ in the $t$ th period

- Obtain updated total head for pumping in the $t$ th period, $H_{T-P H S}^{t}=Z_{t}+h_{1, t+1}+h_{2, t+1}$ 


\subsection{Multi-Objective Optimization Model for Economic and Technical Evaluation of the System}

A bi-objective mathematical model of the PHS-PV system was formulated on the basis of the multi-objective optimization to establish optimum costs and system reliability in this section.

1. Objective Optimization Functions

- Objective function $\mathrm{F}_{1}$ : minimizing the levelized cost of energy (LCOE: defined as a method to calculate energy costs based on operational expenditure (OPEX) and capital expenditure (CAPEX) [37]);

$$
\begin{gathered}
\mathrm{F} 1=\operatorname{minimize}(\mathrm{LCOE})=\operatorname{minimize}\left(\frac{\sum_{n=1}^{N} \frac{I_{e(t)}+M_{t}+F_{t}}{(1+r)^{n}}}{\sum_{n=1}^{N} \frac{E_{G(t)}}{(1+r)^{n}}}\right) \\
I_{e(t)}=I_{e-P V}+I_{e-T b}+I_{e-P p}+I_{e-U R}+I_{e-L R}+I_{e-\text { inverter }} \\
r=i /(1+i)
\end{gathered}
$$

- Objective function $\mathrm{F}_{2}$ : minimizing the loss of power supply probability (LPSP: defined as the percentage of time intervals during which the demand is not fully satisfied [2]).

$$
\mathrm{F} 2=\operatorname{minimize}(\operatorname{LPSP})=\operatorname{minimize}\left(\frac{\sum_{t=1}^{T} D E(t)}{\sum_{t=1}^{T} P_{\text {load }}(t) * \Delta t}\right) \times 100
$$

where $I_{e(t)}$ denotes investment expenditures in year $t ; M_{t}$ denotes operation and maintenance expenditures in year $t(\mathrm{USD} / \mathrm{kW}) ; F_{t}$ denotes fuel expenditures in year $t ; E_{G(t)}$ denotes energy generation in year $t(\mathrm{kWh}) ; r$ denotes discount rate (\%); $i$ denotes interest rate (\%); $n$ denotes lifetime of the technology (yrs.); $I_{e-P V}$ denotes the investment expenditure for PV $(\mathrm{USD} / \mathrm{kW}) ; I_{e-T b}$ denotes the investment expenditure for turbine (USD/kW); $I_{e-P p}$ denotes the investment expenditure for pump (USD/kW); $I_{e-U R}$ denotes the investment expenditure for upper reservoir (USD $\left./ \mathrm{m}^{3}\right) ; I_{e-L R}$ denotes the investment expenditure for lower reservoir $\left(\mathrm{USD} / \mathrm{m}^{3}\right) ; I_{e-\text { inverter }}$ denotes the investment expenditure for inverter (USD/kW); $D E(t)$ denotes the insufficient energy at the $t$ time period $(\mathrm{kW})$; $P_{\text {load }}(t)$ denotes the required load at the $t$ time period $(\mathrm{kW}) ; T$ denotes the total number of time periods in a specific calculation time (hrs.); $\Delta t$ denotes the time interval (hrs.)

2. Decision variables

In this problem, the basic components of the PHS-PV, namely, solar PV and PHS plant capacities, were considered as decision variables.

\subsection{Case Study}

The case study was applied to the cascade hydropower plants along the Shire River originating from Lake Malawi. Lake Malawi is the largest surface water reservoir in Malawi with an estimated surface area of $24,000 \mathrm{~km}^{2}$ supplying water into the Shire River. Table 1 summarizes the existing capacities of the hydropower plants (HPP) along Shire River currently having less capacity than the power demanded. There are three hydropower plants along the Shire River in a cascade mode. Figure 4 indicates the study area and illustrates the aerial map in the system set-up. 
Table 1. The current installed cascade hydropower plants' capacities along Shire River.

\begin{tabular}{cccc}
\hline HPP & Head $(\mathbf{m})$ & Design Mean Flow $\mathbf{( \mathbf { m } ^ { 3 } / \mathbf { s } )}$ & Capacity $(\mathbf{M W})$ \\
\hline Nkula & 50 & 280 & 124 \\
Tedzani & 37 & 280 & 93 \\
Kapichira & 54 & 270 & 128 \\
\hline \multicolumn{3}{c}{} \\
\hline
\end{tabular}

(a)

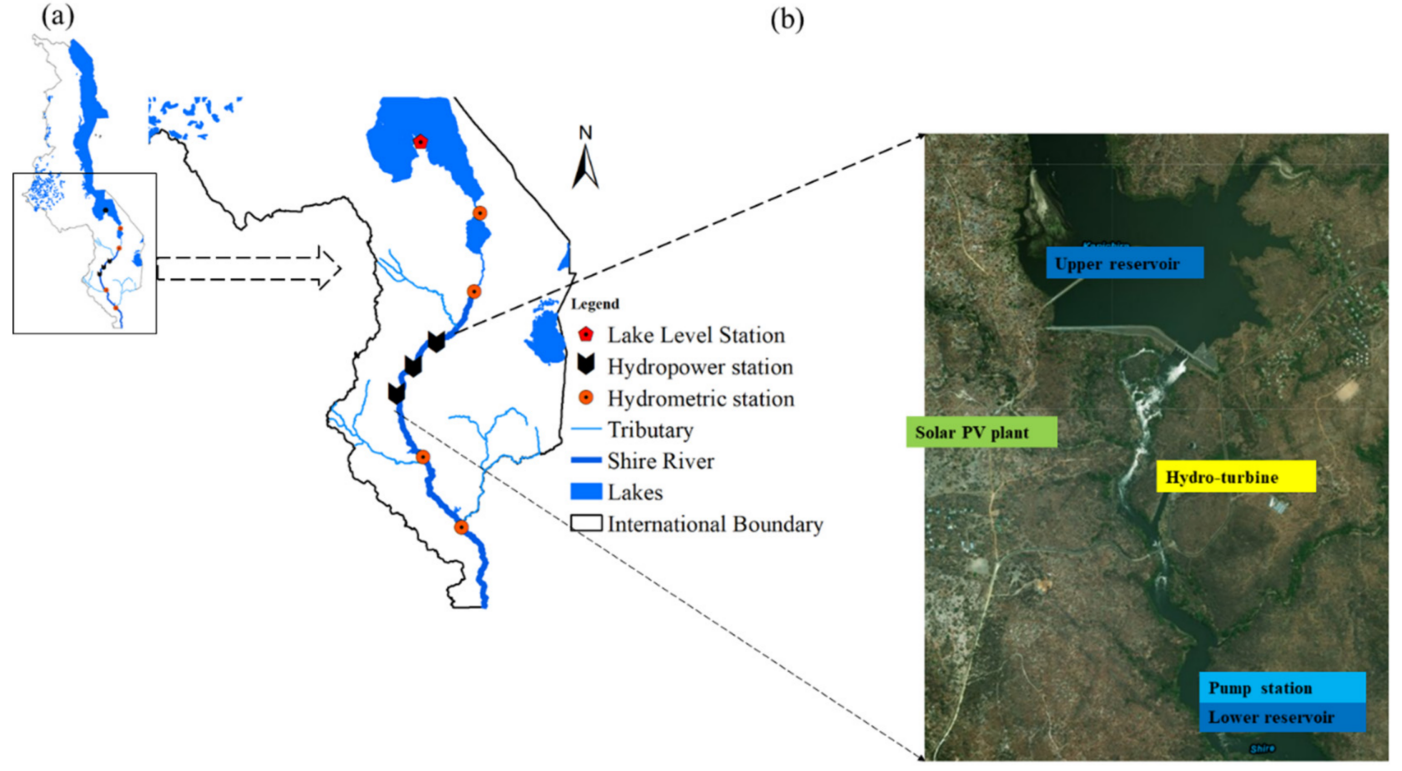

Figure 4. Map of Malawi showing (a) Lake Malawi-Shire river system, (b) the study location for PHS-PV system along the Shire River, Source: Google Earth images.

On the Shire River, runoff discharge was temporary and periodical with high discharge during rainy and winter periods and remarkably lower discharge during dry periods. Figure 5 presents the flow/capacity duration curve for Shire River which indicates runoff inflow and power generation capacity with respect to proportion time of the season.

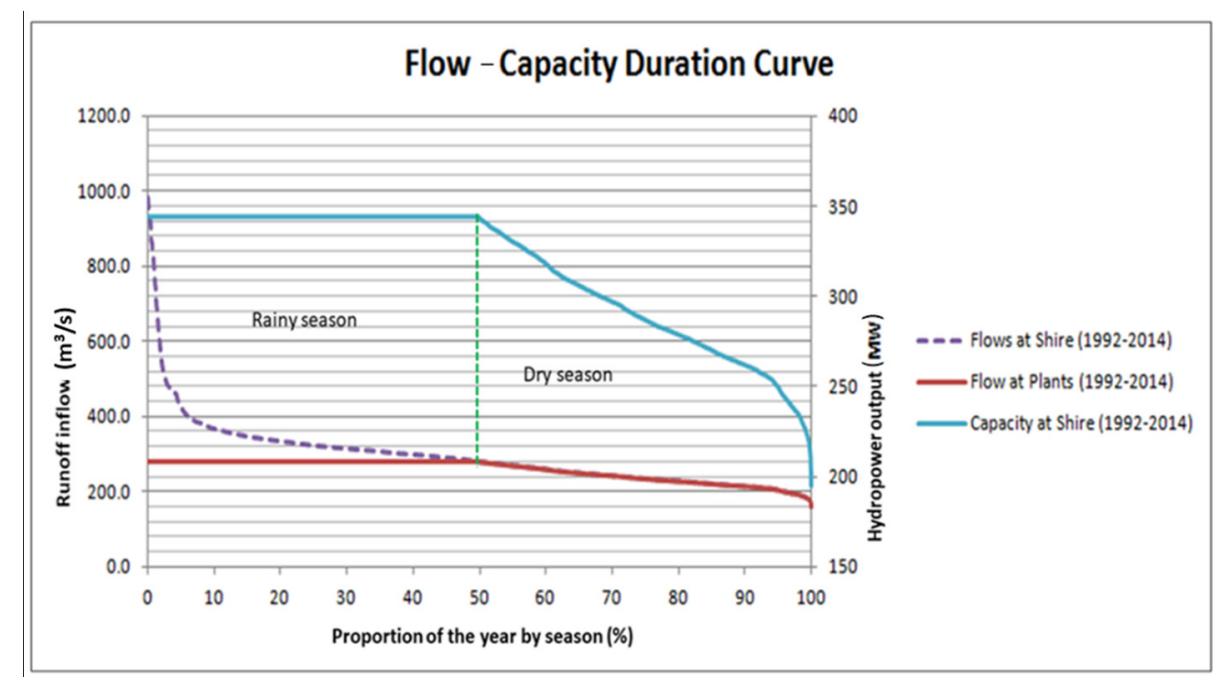

Figure 5. Flow / capacity duration curve for the Shire River in rainy (January-May) and dry (JulyDecember) seasons. 
Notably, in about half of the year during the rainy season (January-May), flows were only partially utilized to generate power due to limited installed discharge/capacity at the plants. During the rainy season, high runoff discharge occurred along the Shire River of up to $1000 \mathrm{~m}^{3} / \mathrm{s}$ that could increase stream inflow into the turbines of the cascade hydropower plants. However, the power plants only generate electricity based on capacity limit of $350 \mathrm{MW}$. Hence, runoff discharge into the run-of-river plants were partially utilized because there was no reservoir with large regulation capacity through which operators could redistribute runoff between the rainy season and the dry season for better energy supply (Figures 5 and 6).

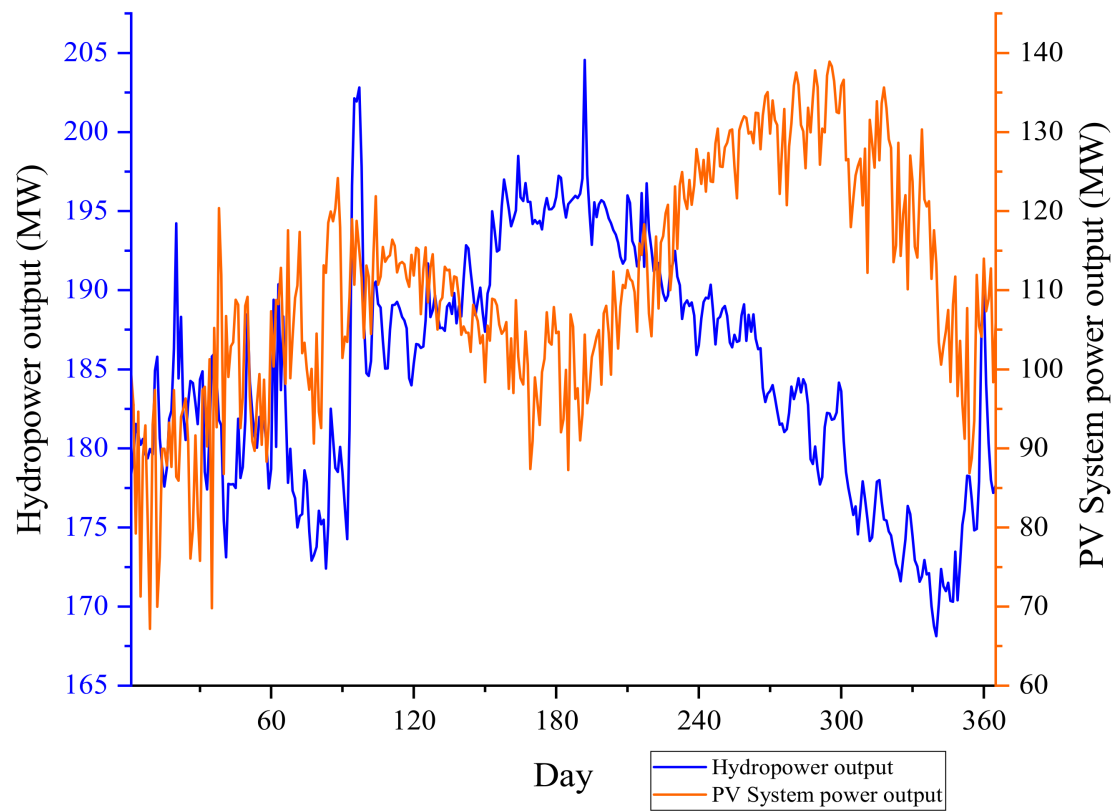

Figure 6. Complementarity of hydro and solar PV power output throughout the year in rainy and dry seasons.

The remaining half of the year, during the dry season (July-December), plants were operated in partial load due to insufficient flows at Shire River. During this period, runoff discharge became significantly lower such that inflows into the run-of-river plants were reduced (Figures 5 and 6). The plants were operated with low flows resulting in short electric power supply from July to December leading to load shedding country wide. Due to short supply capacities at the plants with no large regulation capacity reservoir, a wide gap in power supply was created all year round. Consequently, the country experienced frequent load shedding, insufficient, unreliable, and poor-quality power supply, and unplanned power outages (on average 63 days per annum) [38]. Throughout the year, the runoff discharge was highest during the rainy season and lowest during the dry season while solar irradiation was high during the dry season and lowest during the rainy season (Figure 6). This kind of renewable source availability allowed complementary operation of the hybrid system between the two seasons as shown in Figure 6. The power out from the hydroelectric and PV systems could complement each other in this proposed study easily to satisfy the peaking demand. Therefore, there is a need to increase capacity through the addition of other renewable energy sources. Thus, a complementary hydro/HPS-PV electric system was proposed in this study to operate in a synergetic mode with existing cascaded hydropower plants. In the proposed complementary model, the photovoltaic energy and hydropower from run-off-river plants can meet the load demand throughout the day and/or year with surplus photovoltaic energy providing power to a new pumped storage hydropower station for pumping and storage. Thus, the mix of the run-off-river plants and the new pumped storage hydropower station can supply enough energy during the whole night via a release through turbines. 


\subsection{Simulation Data}

This section describes the data collected for the research, which includes hydropower and runoff data, photovoltaic power output data, load data, and system component associated costs.

1. Hydropower and runoff data

Computation of the hourly hydropower output for the three cascade ROR plants was based on hourly discharge data for a year from July 2015 to June 2016 obtained from the Electricity Supply Commission of Malawi (ESCOM) and Electricity Generation Company Ltd. (EGENCO). These data were historical mean daily discharge data for Liwonde hydrometric station from 1992 to 2016. Since there is no interval inflow between cascade run-of-river plants, the stream runoff was equaled to the runoff inflow into the power plants and upper reservoir. For the PHS system, a fixed speed centrifugal pump efficiency was assumed initially at 0.85 . Additionally, the Francis turbine with an efficiency of 0.90 was selected for this study [39]. The total head was the sum of elevation head of $54 \mathrm{~m}$ and fluctuating headwater level in upper and lower reservoirs $\left(z_{1}\right.$ and $\left.z_{2}\right)$ initially set at $20 \mathrm{~m}$ and $15 \mathrm{~m}$, respectively. The area for the upper and lower reservoir was 900,000 $\mathrm{m}^{2}$ and $450,000 \mathrm{~m}^{2}$, respectively.

2. Photovoltaic power output data

The solar intensity radiation and ambient temperature data from July 2015 to June 2016 for the location were obtained using the PVGIS-CMSAF solar radiation database. PVGIS is an interactive web-based tool [40] that performed an analysis to estimate the PV system power output. The inputs for PV power output analysis in the PVGIS-CMSAF database were the location (latitude of -15.528 and longitude of 34.82 decimal degrees), mounting type (fixed), PV technology (crystalline silicon), nominal PV power (1 kWp), and system losses $(14 \%)$.

3. Load data

ESCOM provided the load demand data for the same period and the researchers further analyzed them to obtain hourly load profiles.

4. System component-associated costs

The investment expenditures of each component of the system that are widely accepted were obtained from existing literature and summarized in Table 2. Since the PHS-PV system components constitute solar PV plant having PV modules, inverters, and control center and the hydro-pumped storage component having a motor-pump unit, charge and discharge pipes, upper reservoir (UR), lower reservoir (LR), and turbine-generator unit. The investment expenditure for each component was estimated, including the operation and maintenance costs of the system. The PV investment was estimated at $2000 \mathrm{USD} / \mathrm{kW}$, inverter at $896 \mathrm{USD} / \mathrm{kW}$ with the other costs for turbine, pump, upper reservoir, and lower reservoir as summarized in Table 2. The maintenance cost was taken as $2 \%$ of total investment cost. Although these costs are related to a particular location, these expenditures are in line with Sub-Sahara African market of the stated components and also widely accepted in the literature.

Table 2. Investment expenditure for each component of the system.

\begin{tabular}{|c|c|c|}
\hline Component Investment Expenditure & Unit & Reference \\
\hline$I_{e-P V}=2000 \times \mathrm{PV}$ rate power $(\mathrm{kW})$ & $\mathrm{USD} / \mathrm{kW}$ & {$[2,19,41]$} \\
\hline$I_{e-T b}=770 \times N_{T}^{0.95} ; N_{T}$ is turbine nominal power $(\mathrm{kW})$ & $\mathrm{USD} / \mathrm{kW}$ & [18] \\
\hline$I_{e-P p}=660 \times N_{P}{ }^{0.95} ; N_{P}$ is pump nominal power $(\mathrm{kW})$ & $\mathrm{USD} / \mathrm{kW}$ & [18] \\
\hline$I_{e-U R}=2.662 \times V_{U R}{ }^{0.7} ; V_{U R}$ is maximum volume of upper reservoir & $\mathrm{USD} / \mathrm{m}^{3}$ & [18] \\
\hline$I_{e-L R}=2.662 \times V_{L R}{ }^{0.7} ; V_{L R}$ is maximum volume of lower reservoir & $\mathrm{USD} / \mathrm{m}^{3}$ & [18] \\
\hline$I_{\mathcal{L}-\text { Inverter }}=896 \times \mathrm{PV}$ rated power $(\mathrm{kW})$ & $\mathrm{USD} / \mathrm{kW}$ & {$[2,19,34]$} \\
\hline$M_{t}=0.02 \times I_{e(t)}$ & $\mathrm{USD} / \mathrm{kW}$ & {$[18,42]$} \\
\hline$i=13.9$ & $\%$ & [43] \\
\hline
\end{tabular}




\section{Results}

\subsection{Power Generation by Cascade Hydropower Plants along the Shire River}

The hourly real-time electricity generation records of the three cascade power plants obtained from ESCOM and EGENCO were used and presented in Table 3 as simulated.

Table 3. Optimized electricity output profiles.

\begin{tabular}{|c|c|c|c|c|c|c|c|}
\hline Time (Hrs) & $\begin{array}{c}\text { Load } \\
\text { Demand } \\
(\mathrm{MW})\end{array}$ & $\begin{array}{c}\text { Cascade } \\
\text { Hydropower } \\
\text { Output } \\
\text { (without } \\
\text { PHS-PV) } \\
\text { (MW) }\end{array}$ & $\begin{array}{c}\text { Output } \\
\text { Summary of } \\
182 \mathrm{MW} \\
\text { Solar PV } \\
\text { System at } \\
\text { Shire (MW) }\end{array}$ & $\begin{array}{c}\text { Output } \\
\text { Summary of } \\
86 \mathrm{MW} \text { PHS } \\
\text { System at } \\
\text { Shire (MW) }\end{array}$ & $\begin{array}{l}\text { Optimized } \\
\text { Cascade } \\
\text { Hydropower } \\
\text { Output } \\
\text { (with } \\
\text { PHS-PV) } \\
\text { (MW) }\end{array}$ & $\begin{array}{c}\text { Optimized } \\
\text { Solar PV } \\
\text { Power } \\
\text { Output } \\
\text { (MW) }\end{array}$ & $\begin{array}{c}\text { Optimized } \\
\text { PHS Power } \\
\text { Output } \\
\text { (MW) }\end{array}$ \\
\hline 1 & 177.294 & 177.294 & 0 & 0 & 177.294 & 0 & 0 \\
\hline 2 & 195.8 & 195.8 & 0 & 6.055 & 189.745 & 0 & 6.055 \\
\hline 3 & 190.3 & 190.3 & 0 & 0.605 & 189.695 & 0 & 0.605 \\
\hline 4 & 189.8 & 189.8 & 0 & 0.11 & 189.691 & 0 & 0.11 \\
\hline 5 & 192.7 & 192.7 & 0 & 2.983 & 189.717 & 0 & 2.983 \\
\hline 6 & 199.96 & 199.96 & 0 & 10.177 & 189.783 & 0 & 10.177 \\
\hline 7 & 233.88 & 233.88 & 0 & 43.791 & 190.089 & 0 & 43.791 \\
\hline 8 & 219.84 & 219.84 & 4.224 & 25.692 & 189.924 & 4.224 & 25.692 \\
\hline 9 & 215.14 & 215.14 & 23.624 & 0 & 191.516 & 23.624 & 0 \\
\hline 10 & 203.66 & 203.66 & 62.191 & 0 & 141.469 & 62.191 & 0 \\
\hline 11 & 212.76 & 212.76 & 114.123 & 0 & 98.637 & 114.123 & 0 \\
\hline 12 & 227.9 & 227.9 & 120.972 & 0 & 106.928 & 120.972 & 0 \\
\hline 13 & 258.654 & 258.654 & 118.087 & 0 & 140.567 & 118.087 & 0 \\
\hline 14 & 248.219 & 248.219 & 106.312 & 0 & 141.907 & 106.312 & 0 \\
\hline 15 & 222.512 & 222.512 & 85.227 & 0 & 137.285 & 85.227 & 0 \\
\hline 16 & 217.946 & 217.946 & 55.319 & 0 & 162.627 & 55.319 & 0 \\
\hline 17 & 220.131 & 220.131 & 20.932 & 9.423 & 189.776 & 20.932 & 9.423 \\
\hline 18 & 227.292 & 227.292 & 2.843 & 34.445 & 190.004 & 2.843 & 34.445 \\
\hline 19 & 271.439 & 271.439 & 0 & 81.011 & 190.428 & 0 & 81.011 \\
\hline 20 & 266.831 & 266.831 & 0 & 76.445 & 190.386 & 0 & 76.445 \\
\hline 21 & 255.911 & 255.911 & 0 & 65.623 & 190.288 & 0 & 65.623 \\
\hline 22 & 233.192 & 233.192 & 0 & 43.109 & 190.083 & 0 & 43.109 \\
\hline 23 & 207.239 & 207.239 & 0 & 17.391 & 189.848 & 0 & 17.391 \\
\hline 24 & 198.555 & 198.555 & 0 & 8.785 & 189.770 & 0 & 8.785 \\
\hline
\end{tabular}

In the power system, two load demand peaks occurred within $24 \mathrm{~h}$ of the day. An initial load demand peak was experienced during hours of the day and another peak demand during hours of the night. It was assumed that the load demand that the cascaded hydropower plants have to satisfy should be the same as the real-time electricity generation. The electricity generation data for the cascaded hydropower plants were the electricity transmission as established by ESCOM (grid operator) and were plotted in graph form as presented in Figure 7.

Two sets of electricity generation exist at the cascaded hydropower plants along the Shire River viz. (i) base generation and (ii) peak generation. Thus, the least amount of power that the cascaded hydropower plants have to produce throughout to satisfy the dispatch electricity fixed by the operator of the grid is the base power generation shown in Figure 8. 


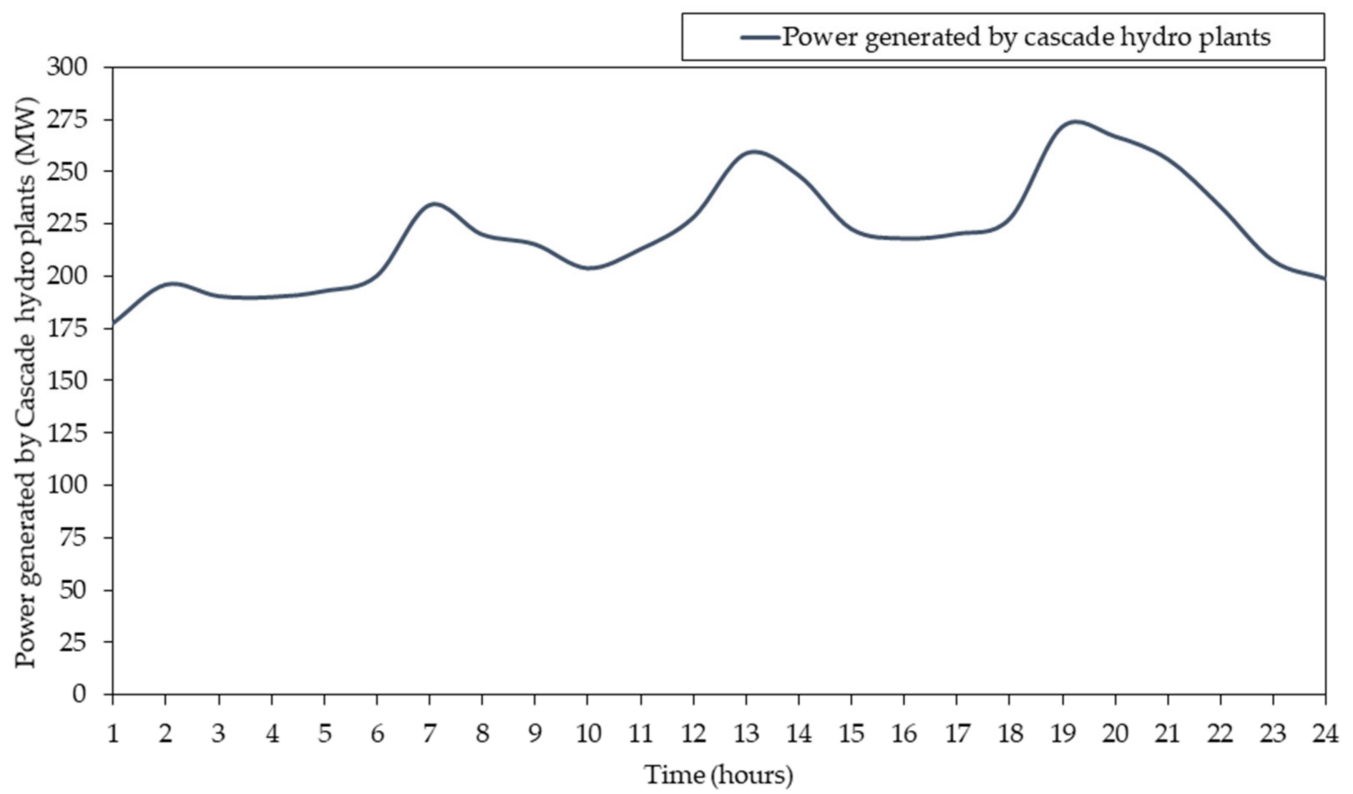

Figure 7. Electricity generation and dispatch by cascade hydroelectric plants through the grid operator (ESCOM).

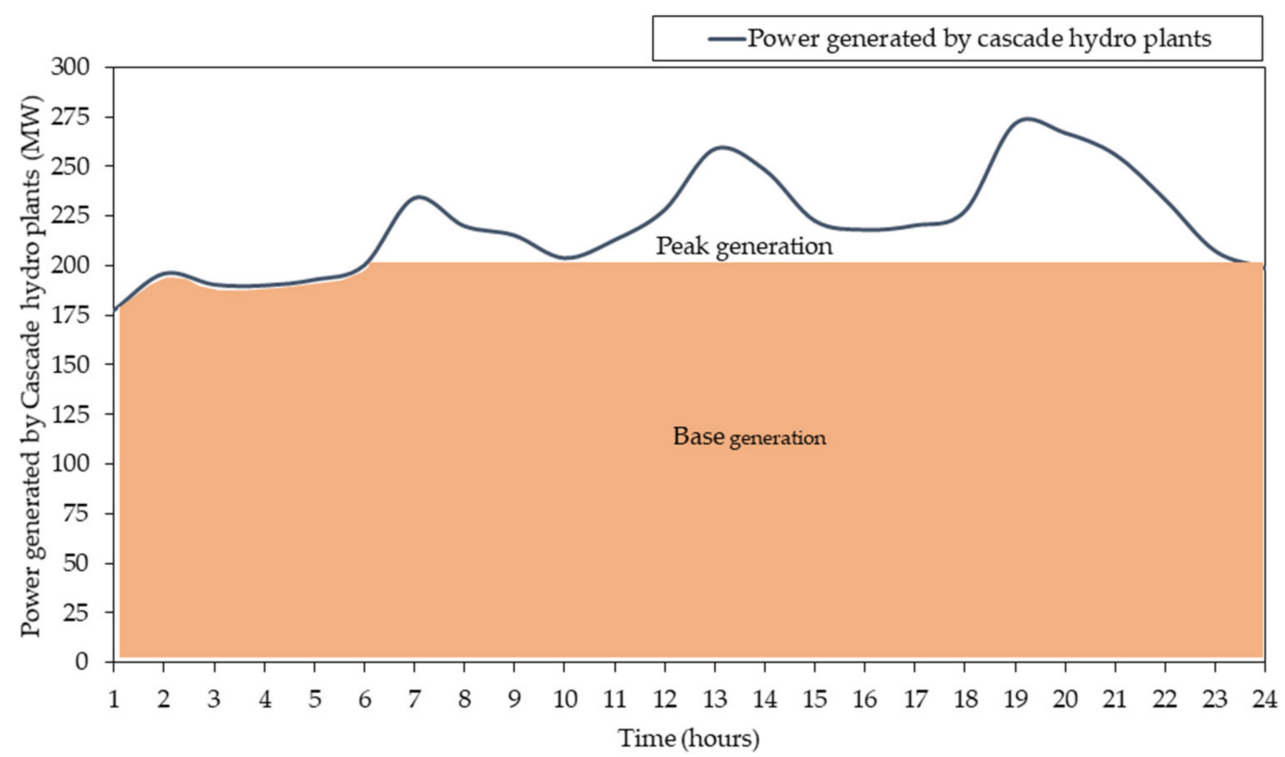

Figure 8. Base and peak generation share.

\subsection{Optimal Results for Load Satisfaction}

\subsubsection{Simulation Results and Software for Optimization}

The assumption of this optimization problem is a linear optimization problem. So, the linear programming method was taken into consideration as an appropriate technique to solve the problem. As such, a linear optimization technique was developed in a MATLAB environment. This approach was selected due to the short computational time to obtain an optimal solution since the solution's search space was confined.

\subsubsection{Optimized Electric Power from the Cascade Hydropower Plants}

The cascaded hydropower plants must satisfy the maximum demand considering the peak and base demand once solar power was not available. Figure 9 presents the optimized scenario. 


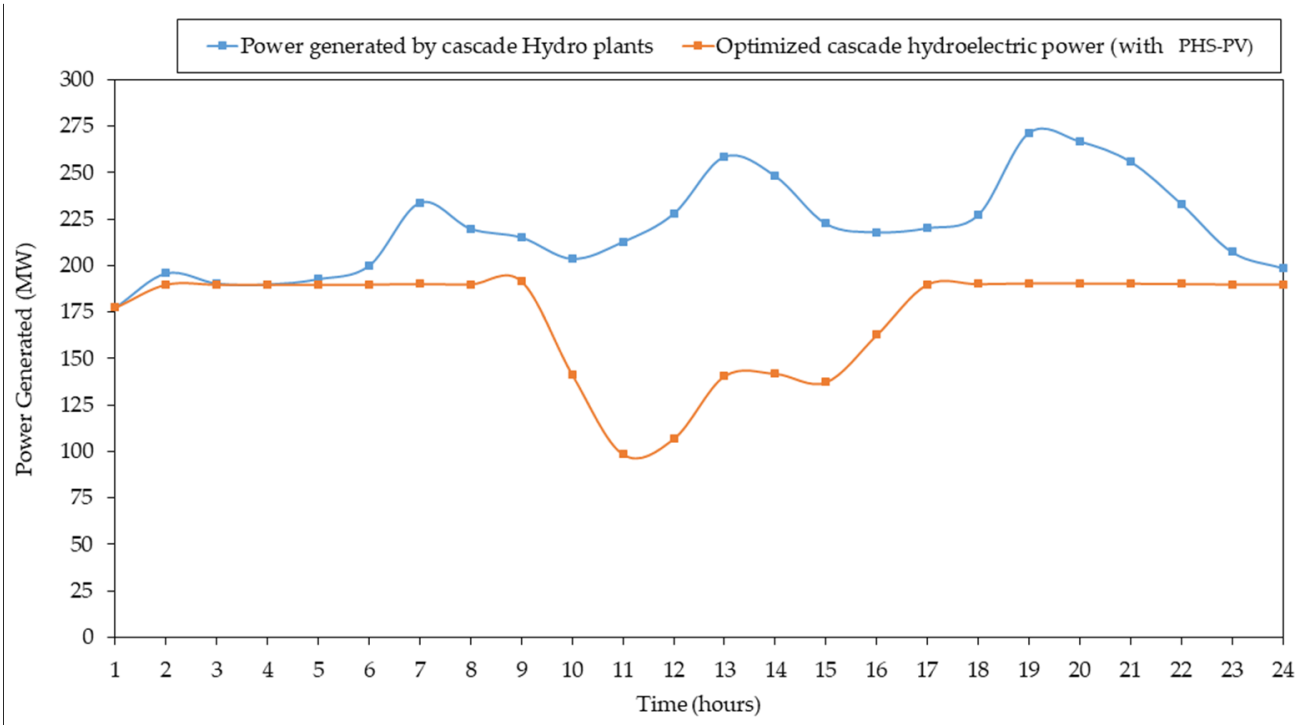

Figure 9. Optimized cascade hydropower output.

The optimized PV and turbine capacities in the PHS-PV system were approximately 182 and $86 \mathrm{MW}$, respectively. These capacities resulted in a reduced amount of power produced during hours of the day by the cascaded hydroelectric plants when solar radiance was in abundance. These results were attained when the electricity dispatch point was the same and operated the solar PV at maximum capacity with any excess power dispatched to the PHS plant for water pumping to the upper reservoir for night-use storage. The cascaded hydropower plants continued to meet the base load demand during the entire day, while the PHS solely satisfied peak electricity transmission time experienced during the night when there was no solar power as a complementary power source to the cascaded hydropower generation. The optimum power dispatch from PV results satisfied a fraction of the day-time peak load with the numerical outcomes presented in Table 3 in Section 3.1. The obtained results indicate that there was $53 \%$ of added power generated by adding the PHS-PV plant. In theory, it can be inferred that the outcome in the optimum power transmission scenario offered benefits as follows:

- Indirect water conservation and low stress on generators

The enormous water discharge via the turbines produces electric power under ordinary situations to generate base power. Thus, the extra amount of water will have to be utilized during peak power periods by the hydropower plants. For the cascade hydropower stations, the turbine generators have to generate extra power to satisfy any existing peak demand that occurs twice within $24 \mathrm{~h}$. As a result, there is a need for surplus the utilization of reserves for water which is never met due to capacity constraints. However, the PHS-PV addition operating in synergy with the cascade hydropower stations conserved any surplus amount of water to be exploited for the daytime peak generation demand. The inclusion of the PHS-PV plant as well its optimized dispatch together with cascaded hydropower plants eased the pressure on electricity generation pressure existing in the turbines as well as the generators of the cascaded hydropower plants since the operational set changed.

\subsubsection{Electric Power from the Solar PV and PHS Plants}

It was presumed that the power output from the solar PV was equivalent to that of the solar electricity output for a particular location as indicated in Figure 10 [39]. Thus, the assumption precisely illustrated the upper limits for power exploitation performance of the solar PV system. The electricity output curve from the solar PV in Figure 10, including the respective mathematical outcomes in Table 3 in Section 3.1, indicated an estimated 29,744 kWh of power produced through the solar PV plant within $24 \mathrm{~h}$. 


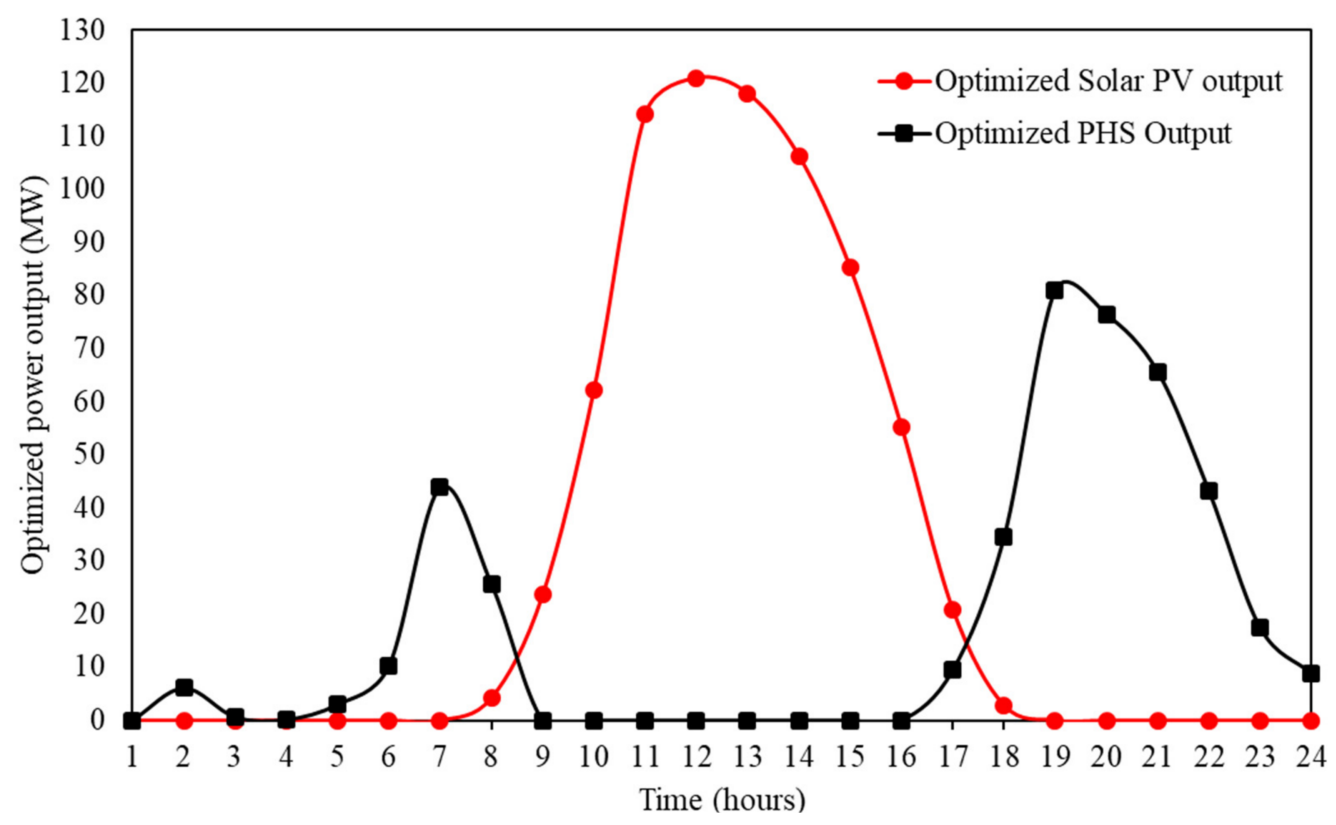

Figure 10. Optimized power output for both PV and PHS plants.

The results in Figure 10 indicated that at any hour of the day, the solar PV plant and the PHS plant responded to provide sufficient power to meet the demand once peak electricity demand was to be satisfied and that any excess energy was dispatched to the pump station for water storage. Therefore, the system operation minimized the electricity output from the cascade power plants with subsequent water conservation in the upper reservoir to produce power generated from turbines at night. It was also observed that this synergetic operation lessened the pressure on the generator at the cascade power plants. Notably, during nighttime operations, the PHS and the cascade power plants sufficed all the available load demands. The electricity for the solar PV plant was simply accessible once solar irradiance was in abundance and dispatched to satisfy peak load demand experienced during hours of the day. The power output from cascade hydroelectric plants was employed to serve the base demand while the PHS plant served the peak electricity demand required from the operator of the grid in the morning hours (6-8 a.m.) and during night time as shown in Figure 10.

\subsubsection{Combined Power Operation of PHS-PV and Cascade Hydropower Plants}

The objective of this study was to employ the solar PV and PHS systems as well as minimize the cascade hydroelectricity output concurrently for several hours. Thus, the typical generation capacity for the entire system continued to be consistent for the share of required electricity to satisfy the peak transmission/demand. Otherwise, the electric power was produced and dispatched via PHS-PV and cascade hydropower into the national grid utilizing the current electric power infrastructure for the cascade hydropower plants. The proposed frame summarizes the outcomes as the cutback to hydroelectric output and the operation of PHS-PV for the matching curtailed hydroelectricity. Figure 11 presents the combined results for the typical hydroelectric generation output from the cascade hydropower plants and the optimized hydroelectricity viz. cascade and PHS and solar PV output. The records/information, as well as the matching output results, were presented in Table 3 in Section 3.1. 


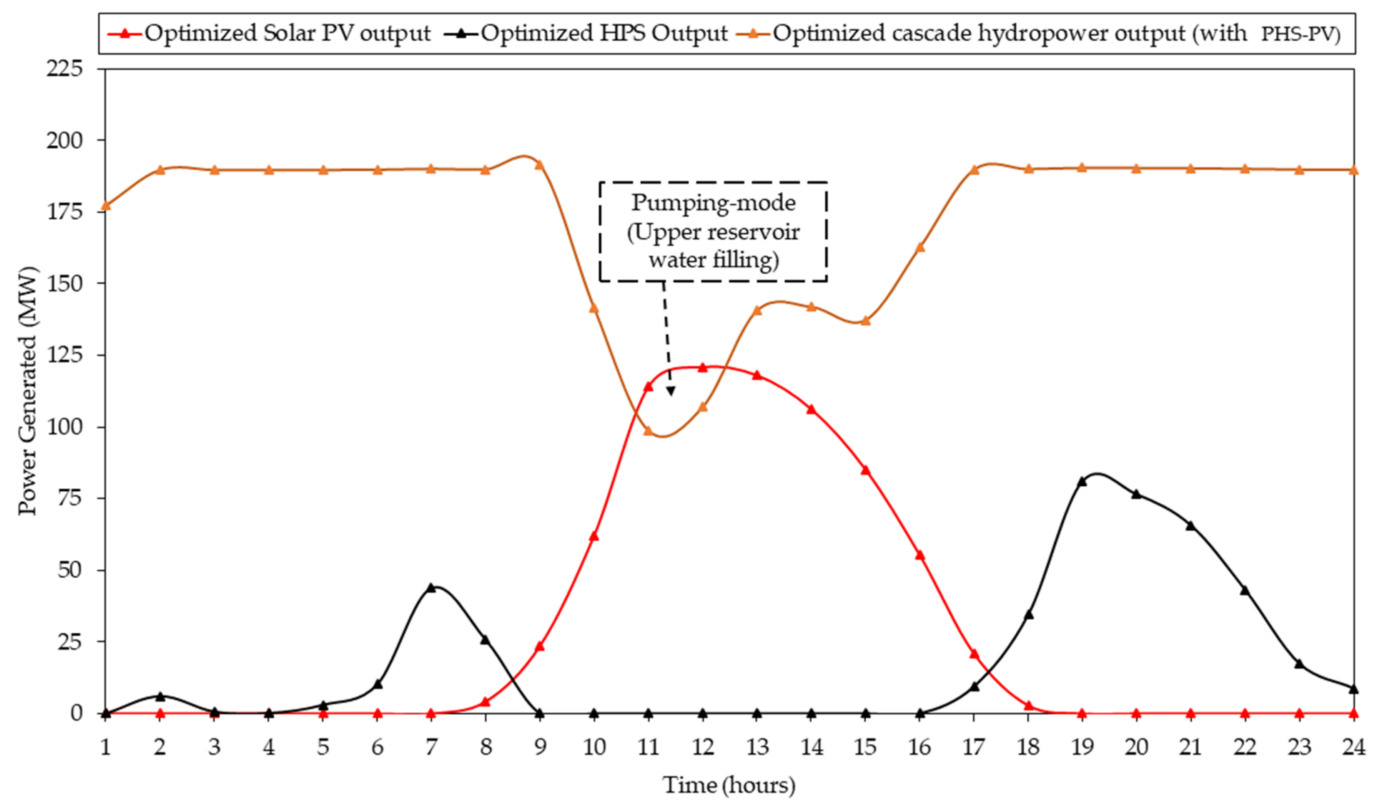

Figure 11. Combined optimized power generation.

The energy produced via the PHS-PV within $24 \mathrm{~h}$ as determined in this investigation was estimated at $47,479 \mathrm{kWh}$, corresponding to above $53 \%$ added electric energy production for the whole system for peak demand during hours of the day. These outcomes imply the efficiency of the suggested PHS-PV combined system considering power dispatch and management in the cascade hydropower plants along the Shire River. The addition of the PHS-PV plant meant that the additional power produced by the cascade hydroelectric plants to satisfy peaking demand for the daytime hours had remarkably declined by the electricity generated via the PHS-PV plant throughout the day. However, the pump station of the PHS system received any excess power generated during the daytime dispatched for pumping to store water for peak demand during nighttime operation. The cascade hydropower plants and the PHS plant generated hydroelectric output to meet nighttime peaking load demand; hence, the study's aim to attain maximum use of the PHS-PV power was established in Figure 11.

\subsubsection{Impact of the Head Effect on Power Production}

This section presents the results on the net head effect on power production. Figure 12 shows the simultaneous variation of hourly daily upper and lower reservoir volumes of the PHS-PV system, respectively.

It is evident that, as the volume for the upper reservoir decreased in the same hour, an increase in the volume of the lower reservoir occurred. Thus, the hourly volume fluctuations between upper and lower reservoirs were complementary due to discharge (turbine release for power generation) and charging (pumping into an upper reservoir for storage), respectively. This variation implies simultaneous changes in the headwater level in both reservoirs. As such, variable water level fluctuations were observed in Figure 13 in the same hour between upper and lower reservoirs.

The net headwater level fluctuated differently: a decrease in water level in the lower reservoir at the same hour resulted in an increase in water level in the upper reservoir due to charging (pumping) and vice versa due to discharge (turbine release). Thus, the fluctuating headwater level corresponded to varying net head effects for either the power generation or pumping mode. As observed, the headwater level significantly varied over the entire scheduling horizon, producing a net head fluctuating between $15.5 \mathrm{~m}$ and $17.8 \mathrm{~m}$. Therefore, the net head effect and impact on electricity generation and pumping discharge of any PHS system cannot be ignored. In addition, the level of water for each time interval was within the upper and lower bounds. Thus, this variation in net head avoided the 
assumption of the constant total head that obtained accurate results for power output in the entire scheduling horizon.

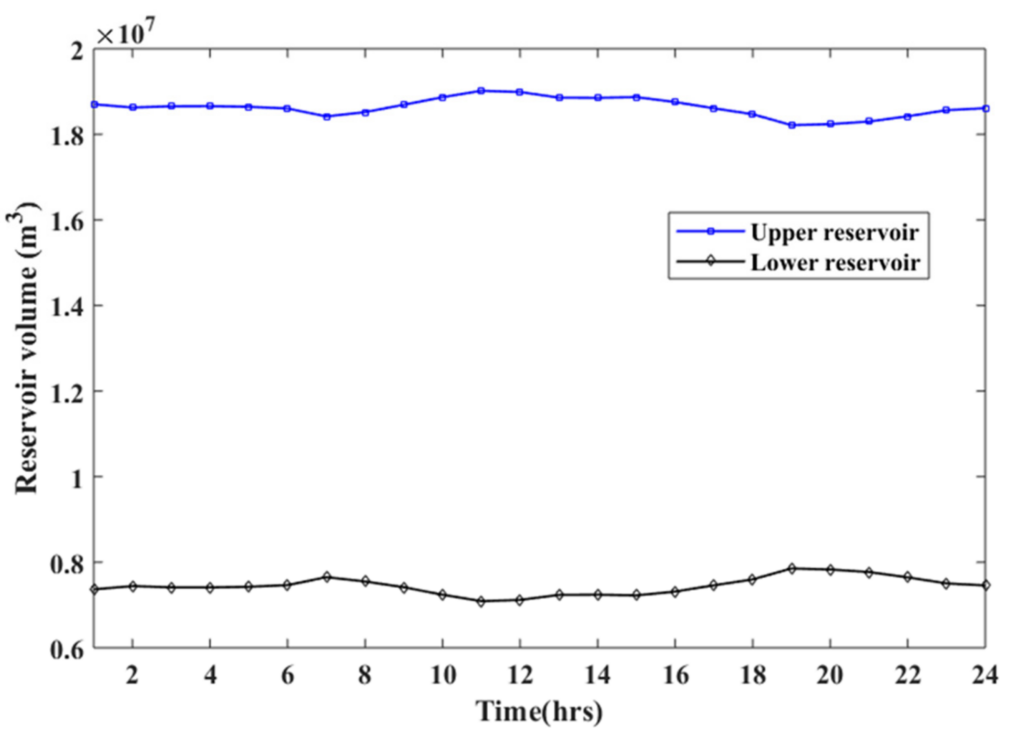

Figure 12. Variable water volume in upper and lower reservoir for entire scheduling horizon.

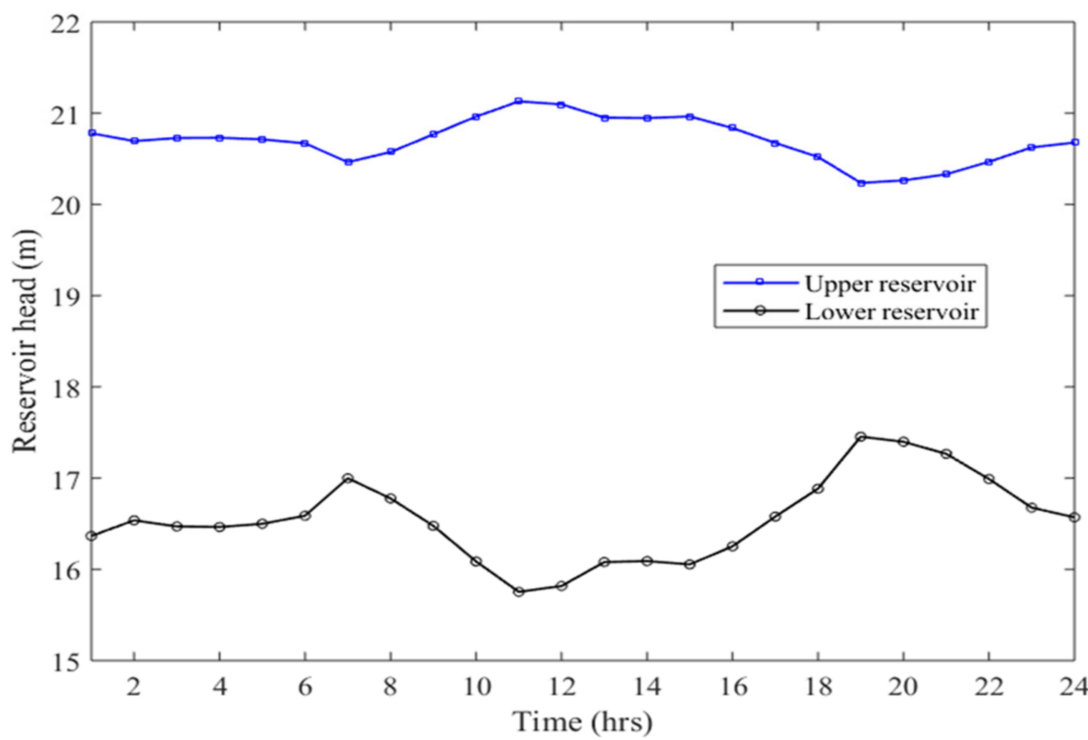

Figure 13. Variable head water level in upper and lower reservoir for entire scheduling horizon.

\subsection{Optimized Techno-Economic Evaluation of the System}

The optimal design at the LPSP of $0.2 \%$ was estimated as presented in Table 4 . This result was based on the multi-objective problem simulation in GA in MATLAB. This value was suitable to the design because it avoided overdesign and under design but provided a better load demand satisfactory rate of $99.8 \%$ throughout the year for the whole system operation. Moreover, this optimal design corresponded to the LCOE of $0.13 \mathrm{USD} / \mathrm{kWh}$ which was close to the current electricity tariffs in Malawi at $0.1 \mathrm{USD} / \mathrm{kWh}$. At this optimal design, the respective matched PV, PHS pump, and PHS turbine capacities approximated at $182 \mathrm{MW}, 31 \mathrm{MW}$, and $86 \mathrm{MW}$ were selected and exhibited in Table 4. Moreover, the estimated capacities for the inverter, upper, and lower reservoir were $1.82 \times 10^{5} \mathrm{~kW}, 2.7 \times$ $10^{7} \mathrm{~m}^{3}$, and $1.35 \times 10^{7} \mathrm{~m}^{3}$, respectively. 
Table 4. Selected design values.

\begin{tabular}{lcc}
\hline Design Parameter & Optimal Solution & Unit \\
\hline Levelized cost of energy (LCOE) & 0.13 & $\mathrm{USD} / \mathrm{kWh}$ \\
Loss of power supply probability(LPSP) & 0.20 & $\%$ \\
PV capacity & 182 & $\mathrm{MW}$ \\
Pump capacity & 31 & $\mathrm{MW}$ \\
Turbine capacity & 86 & $\mathrm{MW}$ \\
Inverter & $1.82 \times 10^{5}$ & $\mathrm{~kW}$ \\
Upper reservoir capacity & $2.7 \times 10^{7}$ & $\mathrm{~m}^{3}$ \\
Lower reservoir capacity & $1.35 \times 10^{7}$ & $\mathrm{~m}^{3}$ \\
\hline
\end{tabular}

Furthermore, Table 5 summarized the investment cost of the components for the selected design. The total investment cost comprised costs for PV modules, pump station, turbine, upper and lower reservoir, operation, and maintenance plus the balance of plant (BOP) cost as defined in [44]. In this study, the number of panels based on the selected $\mathrm{PV}$ capacity of $182 \mathrm{MW}$ at $2 \mathrm{USD} / \mathrm{MW}$ translating to a market price of $600 \mathrm{USD} /$ module of $300(\mathrm{Wp})$ crystalline silicon [45,46]. Additionally, the system could require 606,667 panels having an investment cost of 364 USD ( $84.75 \%$ of the total annualized cost). The investment cost was estimated at 12.20 USD and 37.52 USD for the capacities of the pump and turbine, respectively. The upper reservoir at $0.42 \mathrm{USD}$, the lower reservoir at $0.21 \mathrm{USD}$ with operational and maintenance $(\mathrm{O} \& \mathrm{M})$ costs were estimated at two percent of the total annualized investment costs at 8.29 USD, and BOP at 248.6 USD. Thus, 671.23 USD was the total investment cost for the PHS-PV system.

Table 5. Selected design investment costs.

\begin{tabular}{ccc}
\hline Design Parameter & Capacity/Proportion & Investment Cost (USD) \\
\hline PV modules & 606,667 & 364 \\
Pump & $3.1 \times 10^{4}(\mathrm{~kW})$ & 12.2 \\
Turbine & $8.6 \times 10^{4}(\mathrm{~kW})$ & 37.52 \\
Upper reservoir & $2.7 \times 10^{7}\left(\mathrm{~m}^{3}\right)$ & 0.42 \\
Lower reservoir & $1.35 \times 10^{7}\left(\mathrm{~m}^{3}\right)$ & 0.2 \\
O\&M & $2 \%$ of total investment cost & 8.29 \\
Balance of plant & $60 \%$ of total investment cost & 248.6 \\
\hline
\end{tabular}

Table 6 summarizes a comparison between the LPSP values for the existing cascade hydropower plants and that of the PHS-PV system. Based on the results, the cascade hydropower plants produced an LPSP of $37.91 \%$ that was the status quo at only $62.09 \%$ load demand satisfactory rate exclusive of adding the PHS-PV system into the power system. However, adding the PHS-PV system into the power system remarkably reduced the LPSP to $0.2 \%$, ensuring a $99.8 \%$ load demand satisfactory rate. Moreover, Table 6 indicates that the annual excess output increased approximately 3.4 times following the addition of the PHS-PV system compared to the existing cascade hydropower plants only.

Table 6. Comparison of LPSP between cascade hydro and PHS-PV.

\begin{tabular}{cccccc}
\hline Power Plant & $\begin{array}{c}\text { Load Demand } \\
\mathbf{( k W )}\end{array}$ & $\begin{array}{c}\text { Power Output } \\
(\mathbf{k W})\end{array}$ & $\begin{array}{c}\text { Annual Excess } \\
\text { Output (kW) }\end{array}$ & $\begin{array}{c}\text { Annual Unmet } \\
\text { Load (kW) }\end{array}$ & LPSP (\%) \\
\hline $\begin{array}{c}\text { Cascade } \\
\text { hydro }\end{array}$ & $1.91 \times 10^{9}$ & $1.19 \times 10^{9}$ & $1.94 \times 10^{6}$ & $7.23 \times 10^{8}$ & 37.91 \\
$\begin{array}{c}\text { PHS-PV } \\
\text { plus cascade } \\
\text { hydro }\end{array}$ & $1.91 \times 10^{9}$ & $1.99 \times 10^{9}$ & $8.11 \times 10^{7}$ & $3.8 \times 10^{6}$ & 0.20 \\
\hline
\end{tabular}




\section{Discussion}

This section analyzes the study's hypothesis of the combined complementary operation of the cascade hydroelectric power with the PHS-PV system. The combined complementary operation PHS-PV and cascade hydropower permitted utilizing water storage to improve the peak load capacity of the PHS system and also served the daytime and nighttime load peaks. The simulation outcomes in this proposed optimization concept implied that when the PHS-PV is introduced, the operator for the grid might suggest a larger electricity transmission set point throughout the day. Thus, typically within a day, the hydropower output from the cascade plants was decreased and, subsequently, conserved energy in the form of water storage in day-time hours when solar PV was in abundance. This conserved energy (water stored in the upper reservoir during daytime) could be utilized based on the request from the grid operator for night-time electricity dispatch when there is peak demand as in [47]. The combined complementary operation of cascade hydroelectric power with a PHS-PV system also minimized the stress on turbine generators of hydropower plants for electricity generation. It also removed the requirement of a new substructure to reinforce the PV electricity production since there was an existing electrical transmission infrastructure in use. The variable fluctuation in the net headwater level signified the impact of the net head effect on the electricity generation and pumping discharge of the hybrid system as in [48].

Though the day-to-day generation strategy for the cascade hydropower plants became altered, the day-by-day balance of water in the reservoirs could be sustained to satisfy the evening peak electricity demand. The generated power from the cascade hydropower and the PHS-PV system was initially dispatched fully to the grid with any surplus electricity dispatched to the pump station at the PHS plants for water storage. Thus, this hybrid system indicated that hydropower plants could offer sufficient response while there was a variation in power requirement and solar PV power production. Likewise, these outcomes elucidated that the capacity for solar PV may be utilized for energy production sustainability at the hydropower station. The results also implied that hydropower plants could possibly assist in managing low discharge periods and water availability through setting limits to the hydroelectric plant to run in both the base load mode and peak load mode. However, the gains in operating the optimization model could be grasped to the contrary too; thus, hydroelectricity generation may smoothen the fluctuating solar output through the operation of a "load-following" mode.

The results demonstrated that the optimal design capacities of PV and PHS were 182 and 86 MW, respectively. Additionally, the PHS-PV system is cost effective and reliable corresponding to LCOE of $0.13 \mathrm{USD} / \mathrm{kWh}$ and LPSP of $0.20 \%$ under this capacity proportion. This solution maximized the load satisfactory rate by $99.8 \%$ by minimizing the LPSP by $37.21 \%$ with total investment costs approximated at 671.23 USD. The levelized cost of electricity (LCOE) enables project designers or investors to differentiate the cost of electricity generated by various generation technologies based on variable capital costs, fuel costs, and lifetimes. It is very essential to trace the path of the LCOE among generation technologies to abet policymakers and others find highly economical options. Wu et al. [49] estimated the range for the average total levelized cost of electricity (LCOE) of solar PV for the Eastern Africa Power Pool (EAPP) and Southern Africa Power Pool (SAPP). The LCOE in this case was approximated using resource quality, distance to the nearest transmission line or substation, and distance to the nearest road. In EAPP and SAPP, the range of the LCOE varied considerably among different countries in the Eastern and southern part of Africa. The lower LCOE range of 120-170 USD/MWh was registered among these countries; Ethiopia, Sudan, South Africa, Kenya, Namibia, and Tanzania compared to the rest of the countries. In this study, the estimated LCOE of $0.13 \mathrm{USD} / \mathrm{kWh}$ was obtained for the PHS-PV system. Additionally, considering that the current ESCOM tariffs in Malawi pegged at 0.10 USD $/ \mathrm{kWh}$ while the Southern Africa Power Pool (SAPP) tariffs are pegged at $0.12 \mathrm{USD} / \mathrm{kWh}$ for the peak energy of hydropower plants only, the selected capacities and the LCOE proved that the investment is worthwhile. However, for acceptability of the 
technology by consumers, the 0.03 USD/kWh difference brought about by the PHS-PV system could be subsidized by the government for easy accessibility of electricity to match with the current tariff at $0.1 \mathrm{USD} / \mathrm{kWh}$. Additionally, at this estimated LCOE, investment in renewable energy and for maximum gains of Independent Power Producers (IPPs) is still attractive and within the range of the LCOE for Malawi. This information is vital to investors targeting the African market, including Malawi, which is very attractive currently due to its potential in abundant renewable energy resources which are yet to be exploited. Based on the optimal solution, the key financial indicators (LCOE) improved considerably with PHS-PV added to the cascade runoff river plants. Additionally, development of the Shire River PHS-PV in the cascade could bring reliability in the power supply and represent as one of the key players on the local (and regional) power markets in the long run. Consequently, the Malawian power system will pave the road for the sustainable development of the Malawian economy.

Briefly, this study indicating an electricity output above $53 \%$ on the existing $350 \mathrm{MW}$ hydropower plant system was added after the inclusion of the PHS-PV system. The PHSPV system generation remarkably corresponded to day-by-day peak load and, therefore, operated as a peaking plant for the main grid and, subsequently, let the hydropower plants be employed as a spinning reserve throughout peak load demand times. Briefly, the complementary operation of hydropower with PV systems throughout the country could minimize electricity generation costs together with additional ancillary gains. Even so, whilst these results appear compelling, there were some drawbacks and parts unexplored in the study. For example, the specification of the hardware, type, and actual design of the PHS-PV is a potential study area that needs to be explored in future case studies. The implementation of the PV system on the water surface as a float-PV system could also be explored in the future. The complementary energy mix of hydro pumped storage and solar PV could bring much interest from the developing countries with similar characteristics such as Malawi having a weak electricity grid infrastructure.

\section{Conclusions}

This paper proposed a practical strategy to exploit temporary-periodical runoff discharge by developing a linear optimization model for the pumped hydro storagephotovoltaic system (PHS-PV). The model accounted for the varying net head and power out optimization on the PHS system in both the generation and pumping operation modes. A case study and techniques for integrating and implementing a PHS-PV hybrid system along the Shire River was presented and discussed. Together, PHS-PV produced additional power capacities of $182 \mathrm{MW}$ (solar PV) and $86 \mathrm{MW}$ (PHS-Turbine), respectively. The analysis, herein, showcased the importance of the PHS-PV in satisfying the peak demand requests from the grid operator during day-light and nighttime hours. A bi-objective problem explored the techno-economic optimization by minimizing LCOE and LPSP to obtain LCOE of 0.13 USD $/ \mathrm{kWh}$ and LPSP of $0.20 \%$. The optimized capacities in the model generated above $53 \%$ of added power compared with single-source power generation from the existing hydroelectricity. The PHS-PV system was cost-effective and reliable under this capacity proportion for the load-satisfactory rate of $99.8 \%$. This reliability resulted in overall investment costs for the PHS-PV system approximated at 671.23 USD. This optimization model is very important in regions with similar special run-off characteristics, a power infrastructure, the limited geological landscape for large-scale reservoir construction with large regulation capacity, and a climate such as the Mediterranean regions. Other researchers have previously conducted investigations related to PHS-PV systems and paid more attention to the optimal design of PHS-PV to just regulate output fluctuation of solar energy, peak shaving, smoothing the energy demand curve, or stabilizing the energy flow using a pump station. However, the optimization in this study exploited the temporary-periodic flow, satisfied all day peak electricity demands at a break-even investment cost, and added to the system capacity by at least $53 \%$. Due to its maturity, others have reported that hydro pumped energy storage technology has become the most 
widely utilized large-scale energy storage technology contrasting to the various storage technologies [47] and its optimization is very important. The implementation of modern renewable energy technologies such as PHS-PV might equally complement the long-term energy needs and be a realistic stride with regard to the realization of $30 \%$ access to electricity (goal of the Malawi government by 2030) by incorporating the renewable energy generation.

Author Contributions: Conceptualization, E.C. and C.M.; methodology, E.C.; software, E.C. and Y.Z.; validation, Y.Z., J.L., S.K., and C.M.; formal analysis, E.C.; investigation, E.C.; resources, J.L.; data curation, Y.Z.; writing-original draft preparation, E.C.; writing-review and editing, C.M.; visualization, Y.Z. and S.K.; supervision, J.L.; project administration, J.L.; funding acquisition, J.L. All authors have read and agreed to the published version of the manuscript.

Funding: This work was supported by the National Natural Science Foundation of China, grant number 51722906 .

Institutional Review Board Statement: Not applicable.

Informed Consent Statement: Not applicable.

Data Availability Statement: The data obtained and used for this study are treated as confidential and have restrictions for use by the state agencies.

Acknowledgments: The authors would like to acknowledge the financial support received from The Ministry of Commerce of the People's Republic of China (MOFCOM) in the form of a scholarship to the first author and making this paper achievable. The authors acknowledge the data provision assistance rendered by Klema Hau and Timothy Malata from the Electricity Supply Corporation of Malawi Limited (ESCOM). The authors also acknowledge valuable suggestions and comments from editors and anonymous reviewers who ensured and assisted on improvements performed to this article. The authors also acknowledge the assistance of Janet Chikoja.

Conflicts of Interest: The authors declare no conflict of interest.

\section{References}

1. UN Assembly. Transforming Our World: The 2030 Agenda for Sustainable Development; United Nations: New York, NY, USA, 2015; Available online: https:/ / sustainabledevelopment.un.org/content/documents/21252030\%20Agenda\%20for $\% 20$ Sustainable\% 20Development\%20web.pdf (accessed on 11 August 2021).

2. Mahmoudimehr, J.; Shabani, M. Optimal design of hybrid photovoltaic-hydroelectric standalone energy system for north and south of Iran. Renew. Energy 2018, 115, 238-251. [CrossRef]

3. Kocaman, A.S.; Modi, V. Value of pumped hydro storage in a hybrid energy generation and allocation system. Appl. Energy 2017, 205, 1202-1215. [CrossRef]

4. González, A.; Riba, J.R.; Rius, A.; Puig, R. Optimal sizing of a hybrid grid-connected photovoltaic and wind power system. Appl. Energy 2015, 154, 752-762. [CrossRef]

5. Merkel, E.; McKenna, R.; Fichtner, W. Optimisation of the capacity and the dispatch of decentralised micro-CHP systems: A case study for the UK. Appl. Energy 2015, 140, 120-134. [CrossRef]

6. Margeta, J.; Glasnovic, Z. Theoretical settings of photovoltaic-hydro energy system for sustainable energy production. Sol. Energy 2012, 86, 972-982. [CrossRef]

7. Caralis, G.; Papantonis, D.; Zervos, A. The role of pumped storage systems towards the large scale wind integration in the Greek power supply system. Renew. Sustain. Energy Rev. 2012, 16, 2558-2565. [CrossRef]

8. Margeta, J.; Glasnovic, Z. Exploitation of temporary water flow by hybrid PV-hydroelectric plant. Renew. Energy 2011, 36, 2268-2277. [CrossRef]

9. Deane, J.P.; Gallachóir, Ó.B.P.; McKeogh, E.J. Techno-economic review of existing and new pumped hydro energy storage plant. Renew. Sustain. Energy Rev. 2010, 14, 1293-1302. [CrossRef]

10. Ardizzon, G.; Cavazzini, G.; Pavesi, G. A new generation of small hydro and pumped-hydro power plants: Advances and future challenges. Renew. Sustain. Energy Rev. 2014, 31, 746-761. [CrossRef]

11. Margeta, J.; Glasnovic, Z. Feasibility of the green energy production by hybrid solar + hydropower system in Europe and similar climate areas. Renew. Sustain. Energy Rev. 2010, 14, 1580-1590. [CrossRef]

12. Glasnovic, Z.; Margeta, K.; Omerbegovic, V. Artificial water inflow created by Solar Energy for continuous green energy production. Water Resour. Manag. 2013, 27, 2303-2323. [CrossRef]

13. Rehman, S.; Al-Hadhrami, L.M.; Alam, M.M. Pumped hydro energy storage system: A technological review. Renew. Sustain. Energy Rev. 2015, 44, 586-598. [CrossRef] 
14. Delgado-Antillón, C.P.; Domínguez-Navarro, J.A. Probabilistic siting and sizing of energy storage systems in distribution power systems based on the islanding feature. Electr. Power Syst. Res. 2018, 155, 225-235. [CrossRef]

15. Kougias, I.; Szabo, S.; Monforti-Ferrario, F.; Huld, T.; Bódis, K. A methodology for optimization of the complementarity between small-hydropower plants and solar PV systems. Renew. Energy 2016, 87, 1023-1030. [CrossRef]

16. François, B.; Zoccatelli, D.; Borga, M. Assessing small hydro/solar power complementarity in ungauged mountainous areas: A crash test study for hydrological prediction methods. Energy 2017, 127, 716-729. [CrossRef]

17. Jurasz, J.; Ciapała, B. Integrating photovoltaics into energy systems by using a run-off-river power plant with pondage to smooth energy exchange with the power gird. Appl. Energy 2017, 198, 21-35. [CrossRef]

18. Papaefthymiou, S.V.; Papathanassiou, S.A. Optimum sizing of wind-pumped-storage hybrid power stations in island systems. Renew. Energy 2013, 64, 187-196. [CrossRef]

19. Ma, T.; Yang, H.; Lu, L.; Peng, J. Pumped storage-based standalone photovoltaic power generation system: Modeling and techno-economic optimization. Appl. Energy 2015, 137, 649-659. [CrossRef]

20. Ayotamuno, M.J.; Kogbara, R.B.; Ogaji, S.O.; Probert, S.D. An improved mathematical model for a pumped hydro storage system considering electrical, mechanical, and hydraulic losses. Appl. Energy 2019, 247, 228-236. [CrossRef]

21. Padrón, S.; Medinaand, J.F.; Rodríguez, A. Analysis of a pumped storage system to increase the penetration level of renewable energy in isolated power systems. Gran Canaria: A case study. Energy 2011, 36, 6753-6762. [CrossRef]

22. Juan, I.; Díaz, P.; Jiménez, J. Contribution of a pumped-storage hydropower plant to reduce the scheduling costs of an isolated power system with high wind power penetration. Energy 2016, 109, 92-104. [CrossRef]

23. Kapsali, M.; Anagnostopoulos, J.S. Investigating the role of local pumped-hydro energy storage in interconnected island grids with high wind power generation. Renew. Energy 2017, 114, 614-628. [CrossRef]

24. Chen, C.L.; Chen, H.C.; Lee, J.Y. Application of a generic superstructure-based formulation to the design of wind-pumped-storage hybrid systems on remote islands. Energy Convers. Manag. 2016, 111, 339-351. [CrossRef]

25. Zhang, Y.; Ma, C.; Lian, J.; Chaima, E. Optimal photovoltaic capacity of large-scale hydro-photovoltaic complementary systems considering electricity delivery demand and reservoir characteristics. Energy Convers. Manag. 2019, 195, 597-608. [CrossRef]

26. Abdul Aziz, N.I.; Sulaiman, S.I.; Shaari, S.; Musirin, I.; Sopian, K. Optimal sizing of stand-alone photovoltaic system by minimizing the loss of power supply probability. Sol. Energy 2017, 150, 220-228. [CrossRef]

27. Ould Bilal, B.; Sambou, V.; Ndiaye, P.A.; Kébé, C.M.; Ndongo, M. Optimal design of a hybrid solar-wind-battery system using the minimization of the annualized cost system and the minimization of the loss of power supply probability (LPSP). Renew. Energy 2010, 35, 2388-2390. [CrossRef]

28. Maleki, A.; Pourfayaz, F. Optimal sizing of autonomous hybrid photovoltaic/wind/battery power system with LPSP technology by using evolutionary algorithms. Sol. Energy 2015, 115, 471-483. [CrossRef]

29. Maleki, A.; Pourfayaz, F.; Hafeznia, H.; Rosen, M.A. A novel framework for optimal photovoltaic size and location in remote areas using a hybrid method: A case study of eastern Iran. Energy Convers. Manag. 2017, 153, 129-143. [CrossRef]

30. Lian, J.; Zhang, Y.; Ma, C.; Chaima, E. A review on recent sizing methodologies of hybrid renewable energy systems. Energy Convers. Manag. 2019, 199, 112027. [CrossRef]

31. Portero, U.; Velázquez, S.; Carta, J.A. Sizing of a wind-hydro system using a reversible hydraulic facility with seawater. A case study in the Canary Islands. Energy Convers. Manag. 2015, 106, 1251-1263. [CrossRef]

32. Ma, T.; Yang, H.; Lu, L. Feasibility study and economic analysis of pumped hydro storage and battery storage for a renewable energy powered island. Energy Convers. Manag. 2014, 79, 387-397. [CrossRef]

33. Maleki, A.; Khajeh, M.G.; Ameri, M. Optimal sizing of a grid independent hybrid renewable energy system incorporating resource uncertainty, and load uncertainty. Int. J. Elec. Power Energy Syst. 2016, 83, 514-524. [CrossRef]

34. Ma, T.; Yang, H.; Lu, L.; Peng, J. An optimization sizing model for solar photovoltaic power generation system with Pumped Storage. Energy Procedia 2014, 6, 5-8. [CrossRef]

35. Luo, Y.; Shi, L.; Tu, G. Optimal sizing and control strategy of isolated grid with wind power and energy storage system. Energy Convers. Manag. 2014, 80, 407-415. [CrossRef]

36. Simão, M.; Ramos, H.M. Hybrid Pumped Hydro Storage Energy Solutions towards Wind and PV Integration: Improvement on Flexibility, Reliability and Energy Costs. Water 2020, 12, 2457. [CrossRef]

37. Hansen, K. Decision-making based on energy costs: Comparing levelized cost of energy and energy system costs. Energy Strategy Rev. 2019, 24, 68-82. [CrossRef]

38. Eberhard, A.; Foster, V.; Briceño-Garmendia, C.; Ouedraogo, F.; Camos, D.; Shkaratan, M. Underpowered: The State of the Power Sector in Sub-Saharan Africa. In Africa Infrastrucure Diagnostic Background Paper 6; The World Bank: New York, NY, USA, 2008; Available online: https:/ / openknowledge.worldbank.org/bitstream/handle/10986/7833/482140ESW0P11110Power0Sector0 Review.pdf?sequence=1 (accessed on 20 August 2019).

39. Breeze, P. Power Generation Technologies, 3rd ed.; Newnes: Boston, MA, USA, 2019; pp. 22-35.

40. EU. Photovoltaic Geographical Information System (PVGIS); European Union: Brussels, Belgium, 2019; Available online: https: / / re.jrc.ec.europa.eu/pvg_tools/en/tools.html (accessed on 27 August 2019).

41. IRENA. Solar PN in Africa: Costs and Markets; International Renewable Energy Agency: Abu Dhabi, United Arab Emirates, 2016. Available online: https:/ / www.irena.org/publications/2016/Sep/Solar-PV-in-Africa-Costs-and-Markets (accessed on 10 September 2019). 
42. Papaefthymiou, S.V.; Papathanassiou, S.A.; Karamanou, E.G. Application of Pumped Storage to increase renewable energy penetration in Autonomous Island Systems. In Wind Energy Conversion Systems; Muyeen, S., Ed.; Springer: London, UK, 2012; pp. 295-335.

43. CEICdata. Malawi Bank Lending Rate. Available online: https://www.ceicdata.com/en/indicator/malawi/bank-lending-rate (accessed on 4 September 2019).

44. Rooij, D. Balance of System (BOS): What Is It? Sino Voltaics. Available online: https://sinovoltaics.com/learning-center/basics/ balance-of-system-bos/ (accessed on 4 February 2020).

45. Fu, R.; Feldman, D.; Margolis, R. United States Solar Photovoltaic System Cost Benchmark: Q1 2018; National Renewable Energy Laboratory. Available online: https://www.nrel.gov/docs/fy19osti/72133.pdf (accessed on 4 February 2020).

46. IRENA. Renewable Power Generation Costs in 2018; International Renewable Energy Agency: Abu Dhabi, United Arab Emirates. Available online: https:/ / www.irena.org/publications/2019/May/Renewable-power-generation-costs-in-2018 (accessed on 5 May 2020).

47. Rauf, H.; Gull, M.S.; Arshad, N. Complementing hydroelectric power with floating solar PV for daytime peak electricity demand. Renew. Energy 2020, 162, 1227-1242. [CrossRef]

48. Su, C.; Cheng, C.; Wang, P.; Shen, J.; Wu, X. Optimization model for long-distance integrated transmission of wind farms and pumped-storage hydropower plants. Appl. Energy 2019, 242, 285-293. [CrossRef]

49. Wu, G.; Deshmukh, R.; Ndhlukula, K.; Radojicic, T.; Reilly, J. Renewable Energy Zones for the Africa Clean Energy Corridor; LBNL (LBNL-187271); International Renewable Energy Agency and Lawrence Berkeley National Laboratory: Barkeley, CA, USA, 2015. [CrossRef] 